\title{
Personalization in E-Commerce Applications
}

Anna Goy, Liliana Ardissono and Giovanna Petrone

Dipartimento di Informatica, Università di Torino

Corso Svizzera 185, Torino, Italy

\{goy,liliana,giovanna\}@di.unito.it

Summary. This chapter is about personalization and adaptation in electronic commerce (ecommerce) applications. In the first part, we briefly introduce the challenges posed by ecommerce and we discuss how personalization strategies can help companies to face such challenges. Then, we describe the aspects of personalization, taken as a general technique for the customization of services to the user, which have been successfully employed in ecommerce Web sites. To conclude, we present some emerging trends and and we discuss future perspectives.

Copyright by Springer Verlag. This paper is going to appear in Adaptive Web-Based Systems. P. Brusilovsky, A. Kobsa and W. Nejdl (Eds.).

\section{Introduction}

Electronic commerce includes different types of activities related to the online sales of goods and services. For instance, the ameris glossary defines e-commerce (EC) as follows [10]: "The conducting of business communication and transactions over networks and through computers. As most restrictively defined, electronic commerce is the buying and selling of goods and services, and the transfer of funds, through digital communications. However EC also includes all inter-company and intra-company functions (such as marketing, finance, manufacturing, selling, and negotiation) that enable commerce and use electronic mail, EDI, file transfer, fax, video conferencing, workflow, or interaction with a remote computer. Electronic commerce also includes buying and selling over the Web, electronic funds transfer, smart cards, digital cash (e.g., Mondex ${ }^{1}$ ), and all other ways of doing business over digital networks."

Initially, e-commerce mainly focused on the sales of goods; however, it has then expanded to deal with all the aspects of business interaction, at the individual and at the enterprise level. Two main areas of interest may be identified:

\footnotetext{
${ }^{1}$ www.mondex.com
} 
- Business to Business e-commerce (B2B) concerns the management of business interactions between enterprises.

- Business to Consumer e-commerce (B2C) deals with the interactions between enterprise and end customers.

The most interesting aspect which has determined the increasing success of ecommerce is the fact that geographical and time zone distance is no longer important; in fact, people can be connected to one another at any time and by means of multiple interaction channels, such as e-mail, Web sites, call centers, kiosks, and similar.

- At the enterprise level (B2B), business interactions are greatly facilitated by the continuous and efficient connection between the partners. For instance, the possibility to place orders and monitor their execution and the automated management of the supply chain support an efficient management of business interactions between remote service providers; moreover, they reduce production and delivery costs.

- At the individual level (B2C), customers may purchase goods and services anywhere in the world, at any time. For instance, millions of customers use electronic marketplaces such as ebay [58] to publish products and place orders online, or they use electronic catalogs such as the online retailer Amazon.com [8] to purchase goods and services.

According to recent studies on customer behavior, the adoption of computers and internet connections in households is constantly growing; e.g., August 2004 NielsenNetRatings data shows that the Web penetration in the United States is $74 \%$ of the total population, up $11 \%$ more than one year before. Moreover, a relevant portion of the adult population spends some hours on the Internet every day (for leisure and/or for work) and is reducing the time devoted to TV watching and to traditional shopping. Those people are a promising target of both Internet advertising and eshopping [65].

However, Internet-based interaction poses several challenges to B2C commerce, which traditionally established trust relationships between vendor and customers by relying on face-to-face communication. The absense of human clerks, for instance, brings up the well-known one size fits all issue, as in principle all customers would be offered the same solutions by electronic catalogs. Moreover, not all product types are equally suitable to e-shopping: an electronic catalog enables the customer to read textual information about products, to view pictures and play audio and video content, but the customer cannot have the goods in her ${ }^{2}$ hands. Therefore, while several types of products, such as software, music, books and some high-tech ones, can be directly purchased in an electronic catalog, other products (e.g., garments) are suitable for electronic advertising, but they are most comfortably purchased in a physical store. Neverthless, Web sites are considered as effective tools to advertise most types of goods and most vendors, e.g., in the fashion industry, offer Web sites supporting the personalized search for products.

\footnotetext{
${ }^{2}$ In this chapter we refer to the customer by using the female gender.
} 
Similar considerations hold for services: information services (such as weather forecasts and traffic conditions), booking services (such as travel planning), shipping and transportation services are very good candidates for e-commerce. However, other services require a direct interaction with a human clerk assisting the customer in her decisions. For example, insurance contracts, financial investments, etc. are regulated by Service Level Agreements to be defined on a case-by-case basis with the support of an expert helping the customer to identify the most convenient solution.

A large amount of work has been devoted to address, at least partially, these challenges, with the ultimate goal of improving customer loyalty. In particular, B2C Web sites have been equipped with recommender systems supporting the personalized suggestion of goods suiting individual requirements. Moreover, dynamic configuration techniques have been employed to support the interactive customization of products and services. For instance, several online interactive services support the customization of products or the generation of draft contracts to be revised face to face with a human consultant; the Italian TeleMutuo online loan service [149] is an interesting example of the latter.

\section{Chapter Organization}

The present chapter focuses on personalization in B2C e-commerce and attempts to provide the reader with an overview of that work. In the following we will describe the main personalization techniques which have been applied to customize appearance and functionality of e-commerce Web sites to the individual customer. In order to provide the reader with a complete view on the topic, showing what could be done and what has been done in practice, we will consider both research prototypes and commercial systems. It should be noticed that:

- The former offer advanced interaction and personalization features, but they are usually developed as "closed" systems, which embed proprietary customer and product databases. Thus, they fail to support a seamless integration with the applications broadly used by vendors to manage their business activities.

- The latter are complete systems, supporting the management of product cata$\log$, stock, orders and payments. These systems typically log the operations performed by the users on the Web sites. Moreover, they offer tools to analize the customer behavior. However, they usually support rather simple personalization features to assist the users during the navigation of the product catalog and to tailor the interaction style to individual needs.

In the remainder of this chapter, Section 3 describes the benefits of personalization in $\mathrm{B} 2 \mathrm{C}$ e-commerce, as they have been perceived by retailers and consumers along the years. Section 4 provides some background concepts about personalization and adaptation. Section 5 discusses some perspectives on the management of one-to-one interaction with the customer, describing some of the most well-known e-business infrastructures and some prototype level e-commerce systems which offer advanced personalization techniques. That section ends with a brief discussion about Customer 
Relationship Management and mass customization. Section 6 describes some emerging trends in e-commerce applications and discusses which personalization perspectives are becoming important and which adaptation techniques are being developed to achieve such personalization goals. Section 7 closes this chapter, by presenting some future perspectives.

\section{Benefits of Personalization in E-Commerce}

Personalization strategies have attracted the attention of marketing researchers since about 1990 , but their value has deeply changed along the years. Initially, online retailers aimed at extending B2C Web sites in order to show that they recognized the current user (by means of personalized greetings) and to support the personalized recommendation of off-the-shelf goods. This goal was based on the assumption that a Web site offering a one-to-one kind of interaction would be preferred to an anonymous one.

About 10 years later, the excitement was weaker because there was some evidence that the personalized suggestion of items, taken as a single feature, did not improve revenue enough to cover its costs, at least in small companies. ${ }^{3}$ For instance, in 2003, Jupiter Research released a study according to which only $14 \%$ of consumers declared that a personalized Web site would lead them to buy more often from online stores; moreover, only $8 \%$ said that personalization made them more apt to visit news, entertainment and content sites more frequently. In contrast, $54 \%$ of respondents cited fast loading pages and $52 \%$ cited improved navigation as greater incentives [81, 64].

However, the interest in personalization is growing again. For instance, in 2005 ChoiceStream Inc. published an analysis according to which about $80 \%$ of customers declare to be interested in receiving personalized content, although several people are concerned with sharing personal information with vendors [49]. Moreover, according to the study "Horizons: Benchmarks for 2004, Forecasts for 2005", released in 2005 by consultants BearingPoint Inc. and the National Retail Federation, $48 \%$ of retailers placed personalization high in the list of technologies they would concentrate during 2005.

This growing interest in personalization is mainly due to the increasing demand for Customer-Centric services, which can flexibly react to dynamically changing market requirements [86]. This is a new perspective for Customer Relationship Management (CRM), which aims at improving customers' loyalty by managing, as described by Lynn Harvey (Patricia Seybold Group), "a 'ME-and-YOU' relationship building activity that's focused on companies getting to recognize, understand and ultimately serve their customers" [134].

The Customer-Centric CRM perspective includes the provision of features such as the personalized recommendation of items, but does not limit the offered services

\footnotetext{
${ }^{3}$ Neverthless, some surveys reported optimistic data about Web personalization effects; e.g., see [148].
} 
to this aspect. The idea is that the cost of a CRM solution supporting the storage and analysis of customer information can be balanced by various benefits, among which the availability of knowledge supporting the design of new products matching market trends and a substantial reduction in overhead costs.

While the former aspect is clear, the latter deserves further comments: currently, online retailers benefit from the pervasiveness of e-commerce because they can keep in contact with their customers by means of multiple channels, such as e-mail, Web sites, call centers, physical stores, and so forth. However, all those channels collect large amounts of possibly redundant information, represented in heterogeneous formats. Moreover, customer data continuously change; for instance, people change address and job, they get married, etc., and these changes may influence their needs and interests. As a result, retailers have concrete difficulties in merging the available information and in keeping it updated. Some negative effects follow:

- The lack of data integration and synchronization prevents vendors from effectively exploiting customer information to promote their products and services. For instance, electronic and paper brochures are often delivered to an undifferentiated population, instead of mailing them only to the target customer base of products. The most evident consequences of this problem are high delivery costs and possible junk mail effect on recipients [134, 65, 53].

- Retailers are forced to sustain costs caused by corrupted data; e.g., they often deliver goods to obsolete addresses and they produce wrong bills.

- The lack of tools supporting the analysis of customers' browsing behavior (e.g., shopping cart abandonment) does not enable vendors to collect feedback useful to redesign and optimize their Web sites [70].

In order to face these challenges, some Customer Data Integration (CDI) services are being developed as process neutral modules that can be embedded in complex e-commerce systems to feed operational business processes with reliable customer information. CDI services typically support the fusion of customer data collected from multiple channels and the unified analysis of information data. Besides depicting the situation of an online store in real time, CDI services support the identification of market trends, of successful and unsuccessful products, the segmentation of the customer base and also the definition of business rules supporting the provision of services targeted to specific market segments. Thus, personalization comes into play again, but this time it is supported by vital business requirements smoothing the impact of its cost.

\section{Background}

\subsection{Adaptability and Adaptivity}

The goal of this section is to clarify the main terms of our discussion; to this purpose, we first report the distinction between adaptable systems and adaptive ones [114]. 
- In adaptable systems the adaptation is decided by the user, who explicitly customizes the system to receive a personalized service.

- In adaptive systems, the adaptation is autonomously performed by the system, without direct user intervention.

Adaptable systems enable the user to customize several parameters by choosing the preferred values (e.g., background color and language to be applied in the User Interface). Moreover, some systems enable the user to restrict the features she is interested in. For example, as the Amazon.com retailer has now become a very large Web store, it enables the user to restrict the store catalog by selecting her "favorite stores" (e.g., Music, Electronics, Kitchen \& Housewares, etc.); after the user has selected her preferred categories (stores) the system displays them at the top of the category list for easy access to the most interesting product types.

Although adaptability and adaptivity may co-exist within the same system, the former is a simpler feature and is based on standard system configuration techniques largely applied in interactive and batch software applications. In this chapter we thus address adaptivity, extensively discussed by Brusilovsky in [36, 37] and by Kobsa et al. in [91], and we focus on those aspects that are relevant to e-commerce applications.

\subsection{Target Factors for Adaptivity}

The adaptation of a system may be based on three main categories of information:

\section{Information about the user.}

The type of information to be taken into account depends on the application domain. In several domains, the following user features have been considered: socio/demographic data (e.g., age, gender, job); knowledge and skills; interests and preferences; specific needs; objectives and goals; see [91] for details. In B2C e-commerce, the user is the end customer and the following types of information may be considered:

- The user's knowledge about the domain concepts and the user's skills (i.e., her "know how") can be relevant in the sales of complex products and services; e.g., computers, ADSL connections, and similar.

- The user's interests and preferences usually refer to the categories of products and services sold in the online store, or to specific properties of such products/services. For instance, interest in design versus technological aspects (if the store sells, e.g., hi-tech products), in hard rock versus pop music (if the store sells MP3), in cultural-oriented travels versus sport or fitnessoriented holidays (in case of a travel agency), and so forth.

- The user's needs can include different kinds of information. In particular, the information about disability is important to offer accessible services to impaired people.

- Finally, the user's goals represent the information that is most closely related to the specific application domain; for this reason, goals can assume rather different meanings. For example, an e-commerce system should take into 
account whether the user is buying something for herself or a present for somebody else; a mobile guide might consider whether the user is traveling for business or for pleasure; an online shop assistant might help the user to find the less expensive solution, or the most reliable one, or to balance conflicting requirements.

Although most adaptive systems only consider individual users, in some application scenarios more than one user has to be taken into account at the same time. For example, some recommender systems tailor their suggestions to possibly heterogeneous user groups, such as some tourists traveling together [20], or a family watching TV $[103,15]$. For a detailed discussion about group recommendation, see Chapter 20 of this book [79].

2. Information about the device used to interact with the system.

The customer can access an online store by using a desktop PC, a laptop, a mobile phone, a PDA, an on-board device, or other. Every device has different characteristics, with respect to screen size, computation and memory capabilities, I/O mechanism (keyboard, touchscreen, speech, ...), type of connection, bandwidth, and so forth. These aspects have been classified as environment data by Kobsa et al. in [91].

3. Information about the context of use.

The user can interact with the online store in different situations, e.g., at home, while sitting in a train, walking or driving, or during a meeting. The context category, analyzed in detail by Dey, Abowd and Mynatt in [2,56], is very broad and it is difficult to find a unique definition. Although almost everything can be considered as context of use, for simplicity, we split this category into two main aspects: the physical context and the social context.

- The physical context includes the user location and information about the environment conditions, including light, noise, temperature, time of the connection, walking/driving speed, and other similar features.

- The social context is much more difficult to define and very few applications take it into account. This element, considered in a broad sense, can include features like the social community or group the user belongs to, the task she is performing and the relation with people close to her while she is interacting with the service.

Many researchers include information about the user and the device within the notion of context. In this chapter, we use the term context in the restricted meaning of context of use, including the features mentioned in item 3 above, and leaving the user's characteristics and the type of device employed to access the system as separate categories.

\subsection{Phases in the Adaptation Process}

Kobsa et al. [91] identify three phases in the adaptation process: acquisition, representation/inference, and production. 
1. The acquisition of data about the user, device, and context of use can be supported by the user or automatically performed by the system. In the first method, usually applied when the unobtrusive collection of data is not feasible or convenient, the user is asked to execute some action, typically to fill in a form. The second method relies on the application of intelligent inference techniques (e.g., machine learning, plan recognition, and stereotype reasoning) to acquire information about the user by analyzing her behavior. Advanced technological devices (e.g., sensors, GPS for user location, or on-board equipment for driving speed) may be employed to monitor the user's behavior and to acquire device and context variables.

2. Section 5 briefly presents and discusses the methodologies that can be applied in the second phase, for representation and inference. A detailed analysis can be found in $[36,37,91]$.

3. As far as the production of the adaptation is concerned, it is interesting to specify what is adapted and how. With respect to this criterion, we consider three main broad adaptation features:

- The first one is the suggestion of the product/service, often described as content recommendation. The system may play the role of a recommender, suggesting products and/or services tailored to the user, to the device she is using, and to context features; see Chapter 13 of this book [38]. Moreover, if the online store sells complex products or services, the system can actively guide the customer in the configuration of an item satisfying particular needs and preferences. See Chapters 9 [139], 10 [119], 11 [142] and 12 [40] of this book for details about recommendation techniques. See also Section 5.7 for a discussion about product configuration.

- The presentation of the product/service. Orthogonally to the provision of a personalized recommendation feature, the system may tailor the presentation of items to the user, device and context. For instance, the presentation may use different media, such as written text, speech and pictures; moreover, it may adopt different presentation styles (verbose, synthetic, more or less detailed, simple or technical). The system may also personalize the kind of information about products and services it presents, as well as the presentation style, in order to satisfy different decision-making styles in the selection of products and services. For example, Popp and Lödel [125] apply stereotypical reasoning [132] about customers to recommend products satisfying typical buying preferences.

- The user interface (sometimes referred as structure) may be personalized as well. For instance, the layout, including information and navigation structures, can be modified according to various conditions, including the user's preferences, the limitations of the device and the environment.

Before addressing these adaptation features in detail, it is worth listing some additional aspects, which will not be further discussed in the present chapter. In the first place, the adaptation strategies which will be discussed in relation with e-commerce systems can be applied to a closely related field, i.e., the personalization of Web 
advertisements; e.g., see [95, 22, 84]. Second, three issues, strictly related to the adaptation of the user interface (and partially of the presentation), are addressed in the related work about Human Computer Interaction. Such issues concern the accessibility for users with special needs, virtual reality user interfaces, and usability and design guidelines.

- Accessibility. As discussed in Section 6, the adaptation of the presentation and of the user interface can be based not only on the usage context and on the characteristics of the device, but also on individual user needs and preferences. This kind of adaptation extends the accessibility to people with special needs and has been addressed by several researchers; among others, see [61, 102, 133, 29].

- Virtual Reality user interfaces. Most Web-based user interfaces for e-commerce systems are based on a traditional 2D model. However, some researchers point out that the user experience during the interaction with an online store should be as similar as possible to the real world shopping experience. In this perspective, some authors, such as Chittaro and Ranon, propose a 3D user interface that enables the user to explore a virtual reality environment representing a physical store; see [47] and Chapter 14 of this book [48]. The main goal is to satisfy the needs of those customers that have an emotional style of buying and to enable them to perform natural shopping actions.

- Usability. Regardless of which type of user interface (mobile/traditional, 2D/3D) is offered, an e-commerce system should be usable. Web site usability is a wide research area and a complete discussion of its main issues falls out of the scope of this chapter. We only point out that usability is a prerequisite for the success of an e-commerce site; if the user encounters difficulties in navigating the site, in finding information about products, or in managing her purchases, she might abandon the Web store. Therefore, user interfaces for e-commerce sites should be carefully designed following usability guidelines; see, for instance, the guidelines published by Serco $\mathrm{Ltd}^{4}$ and the article by Tilson et al. [150]. Moreover, as discussed by Benyon in [27], the adaptation of the user interface should improve the usability of the Web site in order to be useful. Therefore, adaptation strategies should be designed and implemented having usability guidelines in mind. For a thorough discussion about this topic, see Gena's survey about usability in adaptive systems [66] and Chapter 24 of this book [67]. Finally, Alpert et al. point out that usability guidelines and User-Centered Design should be seriously considered when deciding which personalization techniques have to be included in an adaptive system: according to the analysis reported in [7], it seems that the users of the ibm.com Web site do not appreciate the attempts to infer their needs and goals; indeed, those users prefer to be in full control of interaction with the system.

\footnotetext{
${ }^{4}$ www.usability.serco.com/research/research.htm
} 


\section{Perspectives on E-Commerce Personalization}

\subsection{Personalization Features in Commercial Merchant Systems}

Along the last ten years, several infrastructures have been developed to facilitate the creation and management of electronic catalogs. For instance, BroadVision [35], Blue Martini Retail [33], Netscape Merchant [111], Microsoft Merchant System $[13,41]$ and IBM WebSphere Commerce [75] have been employed worldwide by enterprises to create e-commerce portals.

One of the main issues to be solved to enable a broad adoption of e-commerce infrastructures is the provision of transactional, secure services and the integration with legacy software that enterprises still use for doing business. All the mentioned systems are strongly focused on these aspects, at the expense of personalization, which they only partially support. However, maintaining a one-to-one relationship with the customer is recognized to be critical to the success of an e-commerce Web site (see Section 5.6); therefore, these systems offer some basic personalization features, mainly concerning the recommendation of products. For example, they support the long-term identification of customers, based on the assignment of identifiers, and the storage of purchase lists, as well as the possibility to track and log each customer's navigation actions. In some cases (e.g., WebSphere Commerce), they allow to define user groups, on the basis of common behavior patterns automatically detected by analysis tools. Moreover, they enable Web store administrators to define simple business rules that can be applied to promote products and propose special offers and discounts, on the basis of the products selected by the customers and/or the visited catalog pages. The discovery of behavior patterns is based on the adoption of knowledge discovery techniques developed in the data mining research area; e.g., see the book by Agrawal et al. [4] and Pierrakos et al.'s survey about Web personalization [122].

As BroadVision seems to be the most successful system, among the cited ones, we will briefly describe some of its features. BroadVision focuses the attention on two personalization strategies.

- In the push approach, the system is pro-active and it guides the user by recommending information and access to applications and features.

- In the pull approach, the system relies on the user who requests information and features and it handles the user's requests in a personalized way.

- Moreover, BroadVision offers the qualifier matching as a filtering strategy, allowing companies to target the delivery of content, the access to applications, and different navigation paths to individual visitors and groups by using qualifiers that match appropriate content and capabilities.

If the company has less complex personalization goals, the rule-based matching can be used. This technique consists of IF/THEN, AND/OR statements to tell the system that it should take certain actions if the Web site visitor meets certain conditions. The actions result in displaying content or granting the access to a part of the site. The business rules depend on the retailer's goals and may be very simple; for example, 
a typical rule triggers the generation of electronic coupons (based on previous purchases) that are sent by e-mail to each customer who has not purchased goods for a while. Of course, the underlying activity carried out by the system in order to choose the rules to be applied along time is very complex, but the Web store administrator does not need to consider it.

It should be noticed that, although the services offered by BroadVision support limited personalization, the wide adoption of this system by e-commerce Web sites and by the enterprise can be explained on the technical side. In fact, the application is built on top of standard technologies such as the Java J2EE [146] and relational databases, which run on Linux, Windows and Solaris platforms, and exist in both commercial environments (such as IBM WebSphere [76] and Oracle [115]), and Open Source distributions (e.g., JBoss Application Server [80]). Therefore, BroadVision guarantees important robustness and scalability features that cannot be neglected in a commercial Web site. Moreover, the system can interoperate in a relatively seamless way with existing databases and legacy software already in use within the enterprise that wants to offer one-to-one interaction with its own customers.

Notice also that, while most merchant systems were initially proposed as proprietary solutions, the current trend is to offer pluggable solutions, which can be seamlessly embedded in the retailer's systems. For instance, WebSphere offers both the suite WebSphere Commerce, supporting the development of a complete B2C ecommerce Web site, and a Customer Data Integration service (WebSphere Customer Center [53]), which enables online retailers to extend their own Web sites with data collection and analysis capabilities.

\subsection{Personalized Recommendation of Products}

Section 5.1 shows that the main adaptive feature offered by commercial merchant systems is the provision of personalized product recommendations, depending on the customer's behavior but based on relatively simple techniques, such as business rules. The question is therefore whether other techniques could be applied, within such systems, in order to enhance their recommendation capabilities, starting from a detailed analysis of the individual customer. In the following, we describe the most popular techniques developed to assist the customer in the selection of items suiting her preferences. In Section 5.7, we will introduce the broader area of mass customization, which concerns the sales of customized products at mass-production costs and relies on intelligent techniques for the design of personalized products meeting the customer's requirements.

\section{Generalized Recommendation Techniques.}

Various researchers have proposed to support the selection of products in different ways. For instance:

- In some cases, an interactive approach is adopted, enabling the customer to search for products according to her own selection criteria. For instance, Sacco 
Recommended for Annamaria Goy (If you're not Annamaria Goy, dick here.)

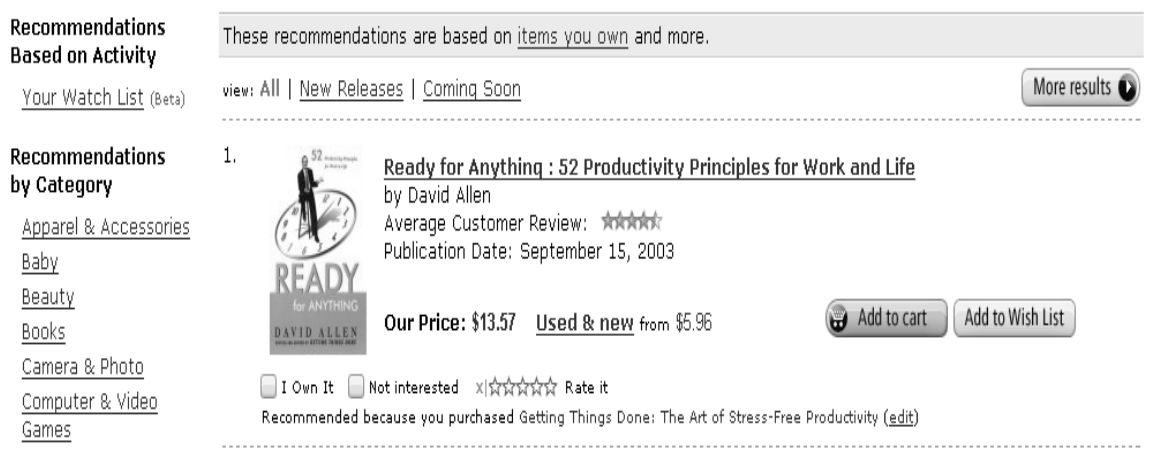

Fig. 1. Personalized recommendation of products in Amazon.com

[135] proposes to utilize dynamic taxonomies, defined by interacting with the system, to classify items and progressively reduce the search space, until the customer isolates a small set of products, which can be compared in detail. The idea is that the electronic catalog should not try to identify the customer's preferences, as she knows them in detail and she can manage the search on her own, if assisted by a search tool. In the same spirit, $\mathrm{Pu}$ et al. propose to enable the customer to specify hard and soft constraints to be satisfied by the solution [128]. In this case, the system proposes suboptimal solutions, which can be criticized and refined in an interactive way, until the customer is satisfied. For more details about the research on "critiquing" see also the work by Burke [39] and by McCarthy and colleagues [105].

- Several e-commerce Web sites also offer additional recommendation features based on data about general customer behavior. For instance, Amazon.com [8] offers a recommendation feature based on the items already bought by the customer (see Figure 1). Moreover, it offers the customers who bought feature (see Figure 2), available in the customer's shopping cart, to inform her about other items purchased by the customers who bought the same items she has selected. Other Web sites offer the similar items or the correlated items features to suggest items closely related to those in the shopping cart. For a summary about recommendation techniques in e-commerce Web sites, see the survey by Schafer et al. [140]. Moreover, see [21] for another interesting perspective on customer behavior analysis: given the importance of users evaluations in the selection of products, Avery et al. propose a model to support a market for evaluations, i.e., "a mechanism for eliciting, sharing, and paying for information", which can be a valuable source of information for personalized recommendation.

- In other cases, inference techniques have been applied to elicit information about the user's preferences or to unobtrusively acquire them on the basis of the user's behavior, in order to identify and recommend the most promising items. See below for details. 
Customers who bought Ready for Anything : 52 Productivity Principles for Work and Life also bought:

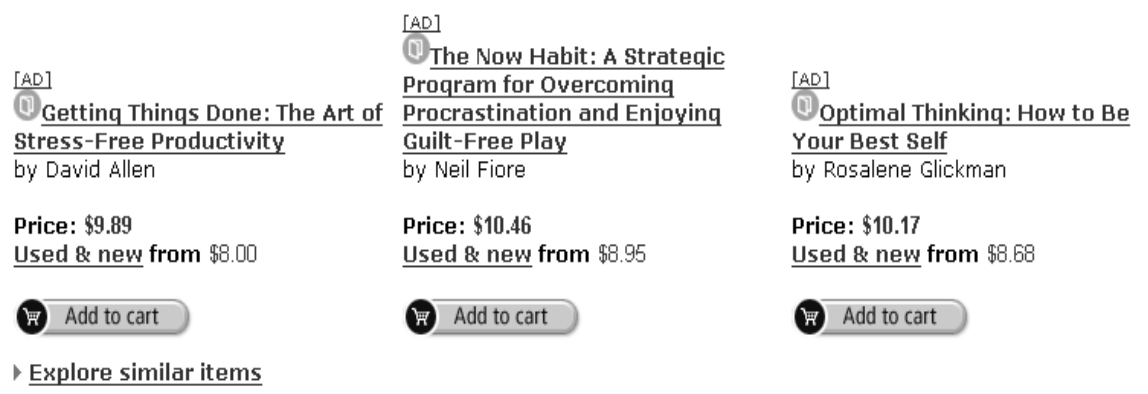

Fig. 2. Customers who bought feature in Amazon.com

\section{Personalized Recommendation Techniques.}

In the User Modeling research, the acquisition of information about user preferences has received a relevant amount of attention and various techniques have been developed to personalize the recommendation of items. Two main approaches have been introduced: $:^{5}$ content-based recommendation suggests the most suitable items for the customer by relying on information about her preferences (interests) and on a description of the item features. Social recommendation techniques employ the preferences of customers similar to the current one for the suggestion; see $[131,60,104,39]$ for an overview of the topic. Specifically, the most well-known techniques that have been developed are content-based filtering and collaborative filtering:

- Content-based filtering recommends goods having properties similar to those of the products that the customer selected in the past; e.g., see [31] and Chapter 10 of this book [119].

- Collaborative filtering is a social recommendation technique; the suggestion of goods is based on the identification of customers similar to the current one and on the suggestion of the items which were appreciated by such customers. Similar customers are identified by analyzing the ranks produced by the whole customer base and the idea is that, if a customer similar to the current one liked a certain item, the current customer will probably like it as well; see Chapter 9 of this book [139].

The two techniques have different positive and negative aspects (see also the discussion in Chapter 12 of this book [40]). For instance:

- Content-based filtering is based on a classification of items, manually or automatically derived from a specification of their features. By applying this technique, new items can be successfully recommended, if a certain amount of information

\footnotetext{
${ }^{5}$ Burke makes a slightly different distinction in Chapter 12 [40] of this book.
} 
about their features is available. However, the individual customer has to be monitored for a while before successfully recommending items; moreover, contentbased recommender systems tend to suggest items similar to one another, at the expense of variety. Furthermore, the accuracy in the recommendations downgrades if there are too many item features to be considered.

- Collaborative filtering does not require detailed knowledge about the items to be recommended, but it is subject to bootstrapping problems. For instance, the recommender is not able to handle items until they have been ranked by a minimum number of customers; moreover, the recommendation capabilities are poor if the matrix storing the product ranks is sparse, because in that case it is difficult to identify customers having tastes similar to those of the current one. Finally, as noticed by Linden et al. in [98], the comparison of ranks produced by customers is very heavy in the case of Web sites, such as Amazon.com, visited by millions of users every day. At the same time, any attempt to reduce the complexity of the algorithm downgrades the accuracy of the recommendations.

Various solutions have been adopted to overcome the drawbacks and limitations of these techniques:

- Hybrid recommender systems have been developed to enhance the accuracy in the recommendations. For example, in the FAB recommender system [23] and in the PTV Electronic Program Guide [116], content-based and collaborative filtering are combined to support high-quality recommendations in the presence of new products and to enrich the variability in the suggestions generated by the system. As Burke discusses in Chapter 12 of this book [40], hybrid recommender systems have also been developed to integrate much more heterogeneous recommendation techniques with the aim of combining complementary types of information about the user in the preference acquisition process. For instance, some systems rely on a combination of Naive Bayes classifiers, Bayesian networks, case-based reasoning, demographic information, and fuzzy classifiers to perform content-based product recommendation; e.g., see [161], [15] and the survey in [39].

- Lightweight recommendation algorithms have been developed to solve scalability issues in heavy-loaded recommender systems. Specifically, collaborative filtering has evolved to the item-to-item collaborative filtering, which computes the similarity among items (instead of customers) in order to recommend items similar to those the customer liked in the past. This algorithm operates on items; thus, its performance does not depend on the number of users accessing the Web site. See [138] for details.

The selection of the recommendation techniques to be adopted in a Web site depends on the characteristics of the application domain. For instance, item-to-item collaborative filtering is particularly suitable for e-commerce sites having relatively stable product catalogs because the ranks may be collected along time. However, other knowledge-based techniques, such as those developed for content-based filtering, might be convenient when the pool of items to be considered changes very frequently. 


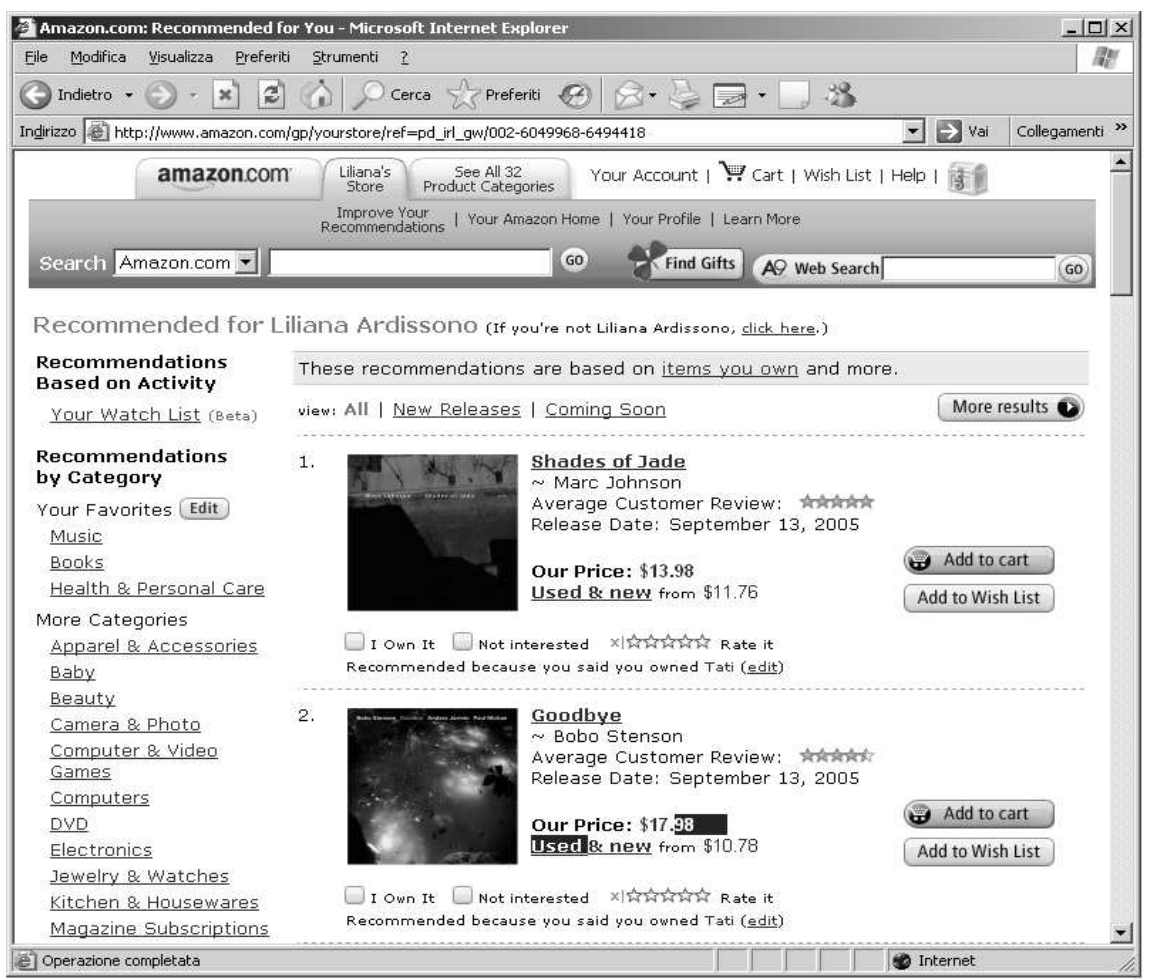

Fig. 3. Recommendation based on customer's owned items in Amazon.com

Before concluding this section, it is worth mentioning the importance of transparency and explanation to enhance the customer's trust in a recommender system. In fact, having received the system's suggestions, the customer should be enabled to deeply understand the content of the electronic catalog in order to make an informed decision. As a thorough discussion about this topic would lead us far away from the focus of this chapter, we only mention that rather different perspectives on the general usefulness and trust issues have been proposed. For example, Herlocker et al. [73] propose to explain recommendations by presenting evidence about the ratings of items provided by people whose purchase histories are similar to the customer's one, or by relying on the rate of good recommendations produced by the system during previous interactions with the same user (a sort of reputation gained by the recommender). Similarly, Amazon.com explains its own recommendations by means of two main features: if the customer has placed some items in her shopping cart, the system may support the recommendations by means of the customers who bought features, discussed in Section 5.2 (see Figure 2). Moreover, if the customer has specified some of the items she already owns, the system may refer to such items in the personalized suggestions; Figure 3 shows a portion of the recommendation list 
in the music category for Liliana Ardissono, who owns Tati by Enrico Rava and has rated that disk very high.

\subsection{Customer Information Sharing}

Regardless of the technique applied within the recommender system, precise information about the individual customer's preferences can only be obtained by observing her behavior for a certain amount of time. Therefore, a delay occurs before the system is able to adapt the interaction to her. This latency issue has been recognized in various application domains and some researchers have proposed to share user information between applications in order to enhance their personalization capabilities. For instance, see the Personis user modeling server developed by Kay et al. [83], the survey about User Modeling Servers by Kobsa ([87], Chapter 4 of this book [89]), and the survey about recommender systems in e-commerce by Schafer et al. [140]. To provide a simple example, two book sellers might share the user models describing their customers in order to increase the knowledge about the common customers and to extend the set of visitors they can handle as known ones.

In commercial applications, broad initiatives have been proposed to support the identification of customers across services; for instance, the Liberty Alliance project [97] grants passports representing universal identifiers associated to users across applications. Although the passport is the enabling technology to support customer information sharing, several issues have to be addressed before customer data can be safely shared by service providers. For example:

- Information sharing has to be controlled in order to respect the customer's privacy preferences, which may be rather articulated. For details about this issue, see Chapter 21 of this book [90], [88, 92] and [158].

- The mutual trust between service providers has to be assessed in order to control the propagation of data. This is important to guarantee that data is not shared with untrusted competitors, or with service providers who would misuse it. See [14] for a preliminary proposal in this direction.

\subsection{Personalized Presentation of Information about Products}

Some efforts have been devoted to enrich electronic catalogs with the generation of personalized product descriptions. In the proposed systems, the presentations are generated "on the fly" and tailored to the individual customer's interests and preferences; see Chapter 13 of this book [38] for a detailed survey of personalized presentation techniques. The personalized generation of product descriptions is based on a declarative representation of the product features and on the adoption of customer preference acquisition techniques that can be employed, at the same time, to recommend the most promising items and to highlight their features accordingly. Different approaches have been developed. For instance:

- Jameson et al. [78, 110] propose to present evaluation-oriented information about goods in order to convince the customer to purchase a certain product. The idea 
is to simulate the behavior of a clerk (e.g., a car seller), who would highlight the product properties having the highest probability to impress the customer. For instance, while presenting a car, a human clerk might focus on information such as the safety and economicity, or on different properties, such as the speed, depending on the customer's priorities. In general, the idea is to provide the customer with a high-level view of the product which satisfies her information needs and highlights the most promising product characteristics.

- Building on Jameson et al.'s interaction model, André and Rist [11] generate multimedia product presentations where animated characters, each one interested in different product properties, criticize products and discuss with one another about their properties.

- Ardissono et al. propose to distinguish the direct user interacting with the system from the indirect users on behalf of whom the user is operating. In the SeTA system [17], multiple beneficiaries are modeled in order to manage the B2C scenarios where expert Internet users may purchase goods on behalf of other people. The system can thus dynamically generate product presentations targeted to the direct user's interests and expertise; however, the properties of items that make them suitable to the beneficiary are highlighted in order to help the customer in the evaluation of products from the perspective of the person who is going to receive them [19].

In the following, we present the approach adopted in the SeTA system in some detail. See the work by Milosavljevic for another initiative concerning the dynamic generation of electronic encyclopedia entries [108]. Moreover, see the article by McKeown [107] for details about a seminal work on tailoring the presentation of information to the individual user.

\subsection{A Case Study: the SeTA System}

The SeTA system $[17,19]$ manages a product catalog that is dynamically generated while the customer browses it, in order to produce highly personalized product presentations. As already discussed, the system tailors the recommendation of items, which is managed by sorting items on a suitability basis, to the preferences of their beneficiary. Moreover, the system tailors the presentation of items to the characteristics of the direct user, in order to meet individual information needs. The separate management of direct user and beneficiary is achieved as follows:

- The system handles an individual user model describing the direct user. Moreover, it enables the user to describe the main characteristics of the beneficiary of the items she is looking for. The model of the direct user is acquired by eliciting some information about herself and by monitoring her navigation behavior. The models of the indirect users are initialized by applying stereotypical information about user classes; see [132] and [17].

- Each user model includes demographic data about the described person (e.g., her age and job), and information about her preferences for products (e.g., she prefers technological products). Moreover, the model of the user interacting with 


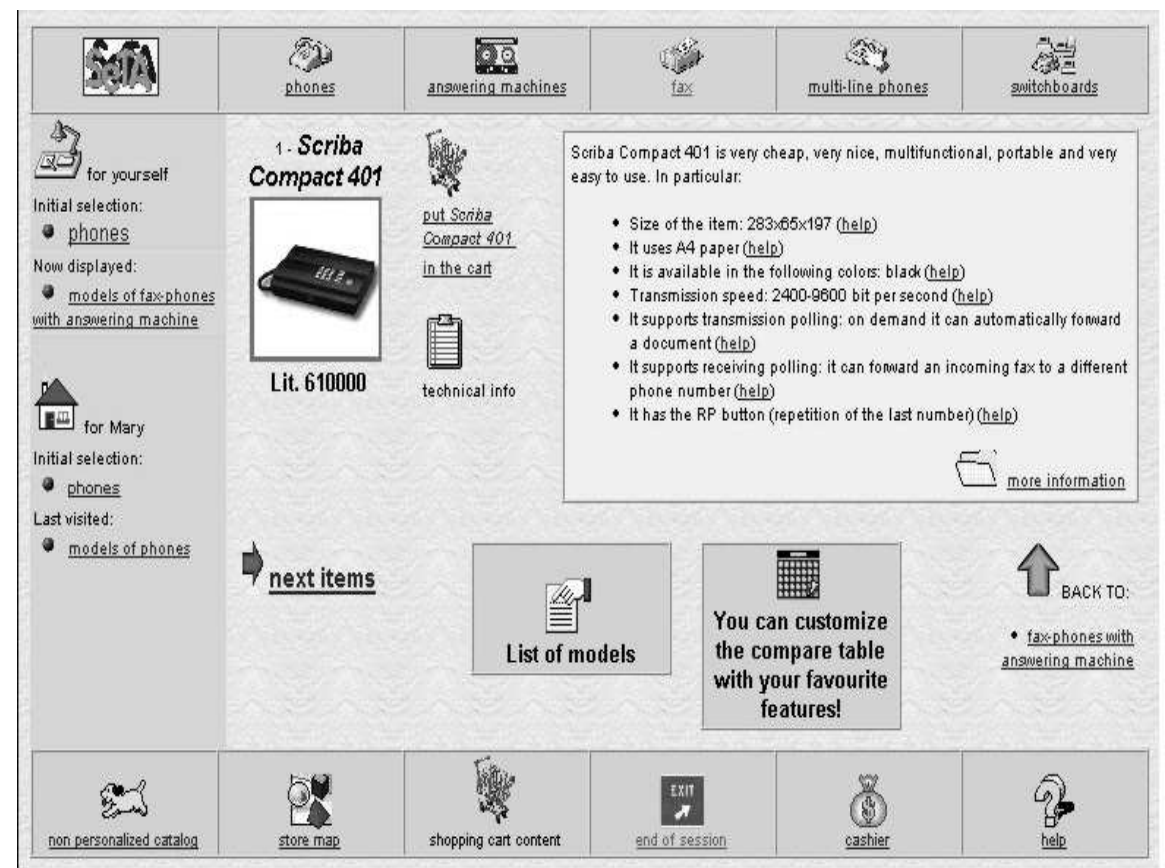

Fig. 4. Product presentation generated by the SeTA system

the system includes information about her features, such as her receptivity (i.e., the amount of information she can elaborate) and interest in different kinds of information about products (e.g., technical details or aesthetic information).

Figure 4 shows a typical product presentation page generated by the SeTA system. The page is structured in various portions that enable the direct user to browse the catalog, view the shopping cart, examine a particular item (the "Scriba Compact 401" fax-phone with answering machine), and so forth. Each item is presented by showing a picture, the price, and a description section which provides the user with detailed information. The description section is organized in two parts:

1. A prologue summarizes the main properties of the item in order to help the customer in the identification of the most promising products before viewing their details. For instance, in Figure 4, the "Scriba Compact 401" product is described by means of qualitative adjectives such as nice, portable and easy to use. These adjectives correspond to the properties of the item that make it particularly suitable for the beneficiary (in that case, the direct user).

2. A list reporting the most interesting technical and non technical features (e.g., size of the item, format of paper used to print out documents, available colors, and similar), ended by a more information link, that enables the user to view the complete product description. 


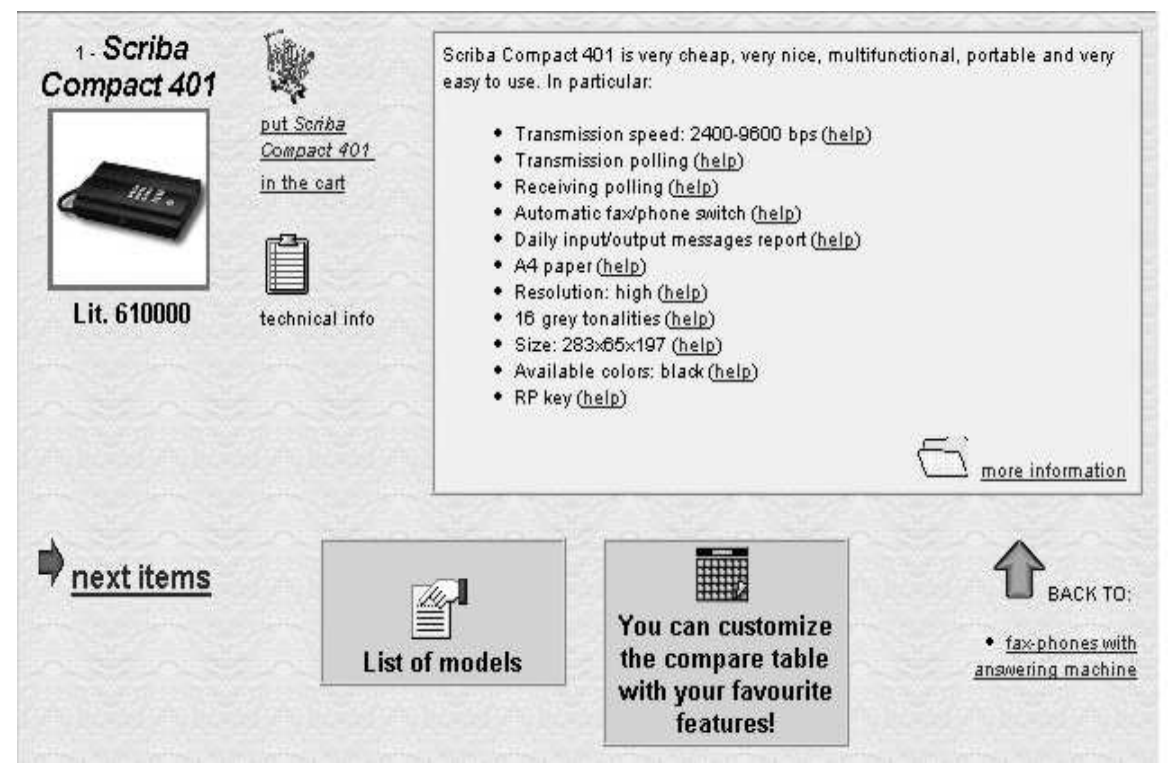

Fig. 5. Detail of product presentation generated by the SeTA system

The summaries and the detailed descriptions are tailored to the direct user: the number of features listed in the page depends on her receptivity and the descriptions are more or less technical, depending on her expertise about the products of the catalog. Figures 4 and 5 describe the same item, but they are tailored, respectively, to a non expert and to an expert user; the two pages show different lists of features of the presented item; moreover, the former page is non technical, while the latter has a more synthetic and technical style. The product descriptions are produced by applying canned text natural language generation techniques supporting a fast generation of correct sentences. See [16] for details.

The selection of the features to be shown in the main portion of the page is aimed at reducing the information overload on the user and at focusing on the most interesting aspects of the product, leaving other details available on demand. Two factors are taken into account in the presentation of features: on the one hand, the catalog should mirror the (direct) user's interests, in order to provide her with relevant information. On the other hand, the vendor might want to guarantee that certain pieces of information are always presented. In order to take these two factors into account, each product feature is given an importance value, defined at Web store configuration time, which specifies whether it is a mandatory piece of information for the product category or not (e.g., price is mandatory for all products). Moreover, each feature is classified in a typology (technical, aesthetic, etc.) corresponding to some user interest types. During the interaction, the importance of each product feature is combined with the user's interests, in order to select the set of features to be shown in the main page and to filter out those to be made available on demand. In this way, the man- 
ager of the electronic catalog can impose constraints on the presentation of strategic or mandatory data; moreover, the customer is shown the most interesting features, from her point of view. For transparency purposes, the customer is always allowed to access complete information about products, by following more information links.

In addition to the personalized presentation of products, SeTA supports the generation of personal views of the catalog by providing interactive functions. One of the most interesting ones is the generation of a customized compare table (see button in the lower portion of the page in Figures 4 and 5), which enables the user to select the products and the properties or features to be considered in the comparison. This table enables the customer to evaluate products on the basis of the aspects most important to her. Moreover, it is an excellent source of information for user modeling because it enables the system to unobtrusively identify the customer's priorities.

The experience gained in the development of SeTA was very interesting, especially because it highlighted positive and negative aspects which we believe are common to many Adaptive Hypermedia systems. On the one hand, the adoption of advanced user modeling and dynamic content generation techniques, together with personalized recommendation mechanisms, supported the generation of electronic catalogs meeting individual user needs with high accuracy. The experiments which were carried out in laboratory tests proved that the users were happy about the presentations and suggestions they received and some of them were particularly interested in the interactive features offered by the system, such as the personalized compare tables. The positive evaluation received by the personalization features of the SeTA system suggested that adaptivity can effectively improve the user interaction in an e-commerce Web site and encouraged us to continue the investigation of the benefits of personalization in such systems.

On the other hand, the major obstacle to a real-world exploitation of SeTA was the knowledge intensive approach supporting the system adaptation. This effort may discourage the Web store designer, who is responsible for the introduction of detailed information about the characteristics of customers and products that have to be modeled. In most cases, the problem is not related to the amount of information to be provided, but to the conceptual effort imposed on somebody who is expert in the sales domain, but not necessarily familiar with knowledge bases and ontologies. Moreover, the designer often has problems in understanding the relation between the domain knowledge introduced at Web store configuration time and the adaptation effects achieved at run time. These difficulties, related to the knowledge acquisition process, could be mitigated by approaches aimed at supporting the knowledge engineer at different levels. For instance, natural language processing and information extraction techniques may be employed to automatically extract information about products, starting from the available documentation [5, 50]. These approaches, coupled with the current work on the automatic acquisition of ontologies (see, e.g., $[113,6]$ ), promise to address the knowledge-based design issue in an effective way. Thus, the work to be carried out by the Web store designer can be dramatically reduced. 


\subsection{Customer-Centric CRM - Advanced Personalization in B2C E-Commerce}

In the last decade, Customer Relationship Management (CRM) has become a keyword for the enterprise marketing strategies, i.e., the Customer Relationship Management (CRM). The business model underlying CRM is defined as being customercentered, instead of product-centered, and can be viewed as a business strategy that enables a company to implement, manage and keep long-term relationships with its customers. Obviously, the ultimate goal of any company is still to increase its profits, but the new idea is that this economic advantage can be reached by increasing customer loyalty, rather than gaining market share through the acquisition of new customers. This principle could be rephrased as "They [marketers] aim not to find customers for their products and services but to find products and services for their customers" [69]. Indeed, the principle represents the core idea of the milestone book by Peppers and Rogers [120], that introduces the idea of share of customer, replacing the traditional share of market. However, customer loyalty implies long-term relationships, that are based on customer satisfaction [130,160]; in turn, customer satisfaction can be achieved by offering products and services fitting the customer's needs and desires and by supporting an individual and personalized interaction. In this perspective, the relationship between the company and its customers becomes one-to-one; the company takes care of any single customer, and it takes her individual needs and preferences into account in order to manage personalized dialogs and to offer tailored solutions. For these reasons, different from traditional marketing strategies, CRM requires a bi-directional, interactive form of communication between company and customer.

The inclusion of adaptation and personalization techniques in an e-commerce site could support CRM in various directions. In the first place, information about the behavior of a large number of customers can be automatically collected and stored. That information can then be further analyzed by data warehousing and CRM tools [85] in order to support cross-selling and up-selling operations ${ }^{6}$. Moreover, the techniques supporting a personalized interaction based on the management of individual user models can play a key role, because they enable the e-commerce site to know its customers at the individual level. Of course, each individual user model should be dynamically updated, on the basis of the user's behavior, in order to support the adaptation to changing interests and needs. The idea is that the longer a customer interacts with a company's site, the more her user model is precise and accurately reflects her needs. An accurate user model can then support the proposal of personalized offers to improve the customer's loyalty and thus the company's profit, in the medium-long term.

Notice that, as Peppers and Rogers claim [121], human interaction is still critical for most people when making decisions. In this perspective, personalization features

\footnotetext{
${ }^{6}$ Cross-selling is the improvement of sales by offering a product or service complementary with respect to the one the customer is interested in; e.g., proposing a printer when the customer is looking for a PC. Up-selling is the operation of selling a product/service having higher quality and price with respect to the one the customer is interested in; e.g., presenting a smart phone instead of a standard mobile.
} 
supporting one-to-one relationships can improve the feeling of a human-like interaction, and they can contribute to improving the quality of the technology-mediated interaction between customers and companies [32]. The shopping assistants proposed by Krüger et al. are examples of systems that go in the same direction; these authors describe Web agents aimed at "providing additional value to the shopping experience in the form of conversational dialogues, multimodal interaction, augmented reality, and enhanced plan recognition" (Chapter 17 of this book [94]). A related idea is the one by Pine and Gilmore [124], who claim that, in order to be more competitive, companies will move from the provision of services to the provision of experiences. This means providing the customer with a sensation, supported by her active participation in an event that can be personalized according to her needs and preferences, thus improving the effectiveness of the experience itself.

One of the main applications of CRM principles is mass customization, which aims at enhancing the flexibility of the production model in order to create products and/or services tailored to individual customer needs, while maintaining mass production efficiency and costs. The importance of personalization within mass customization processes is underlined by Gilmore and Pine [68] and is discussed in the next section.

\subsection{Mass Customization and the Recommendation of Complex Products and Services}

In the past, the mainstream of $\mathrm{B} 2 \mathrm{C}$ e-commerce focused on the sales of off-theshelf goods, such as books, and of products available in a fixed set of pre-configured alternatives, such as phones available in different colors and including or excluding a small set of optionals. However, the manufacturing industry has recently moved towards a more flexible production model, in order to meet an increasing need for individual solutions at affordable costs.

Although enabling the customer to design her own products is very challenging, this possibility has been offered by several major firms, in order to satisfy customers by providing them with very specific products. However, the availability of several configurations would impose the production of an excessively large variety of alternatives. The term mass customization has been introduced to describe the solution to this problem, i.e., the production of customized products at mass-production costs [152]. The idea is to produce customized items within stable processes and structures, which enable the industry to reduce fashion risks and overstock problems.

The customization of products is typically supported by the development of configuration systems (e.g., see [77]) that enable the customer to generate solutions starting from the specification of functional and aesthetic features. In some cases, e.g., as far as high-tech products are concerned, these systems are available in Web stores and they enable the customer to remotely design products. In other cases (e.g., in the sales of garments and shoes), fit requirements impose a direct and physical contact with the customer, in order to acquire detailed information about her; after the acquisition of such information, the configuration activity can be performed online at any time. 


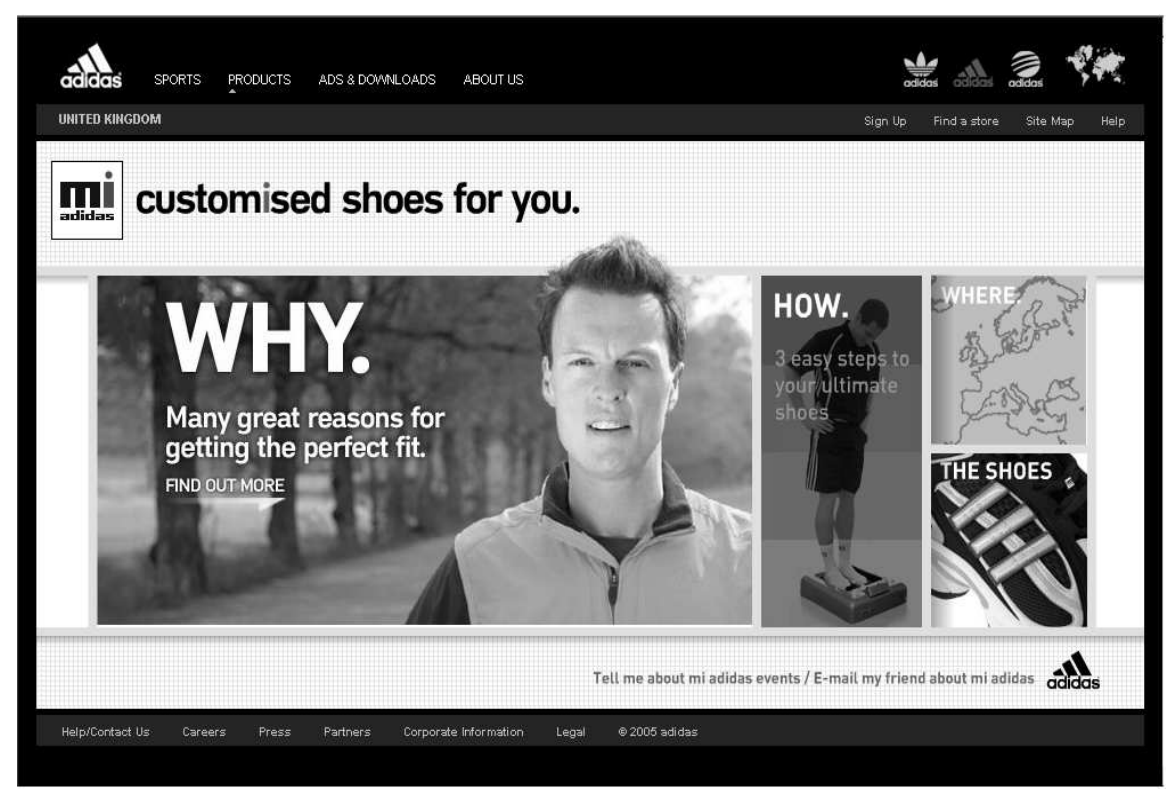

Fig. 6. The miAdidas Web site

In the footwear industry, some major firms have adopted the mass customization approach for the production of their goods. For instance, the "mi Adidas" program (see Figure 6 and [3]) offers a foot scanning service available in selected stores and at special events which enables the firm to store the customer's measures and produce shoes fitting her feet at any time. After the customer's footprint has been acquired, she can customize as many pairs of shoes as she wishes, by choosing fabric, color, and other aesthetic features [28, 123]. The "mi Adidas" case suggests that mass customization has the potential to enhance the relationship between customer and vendor: once the customer has spent her time to specify personal preferences and create her own product, she will likely reuse her profile when customizing other products. However, as discussed by Berger and Piller in [28], "there is still only very little understanding about the perception of choice and the joy or burden of co-design or configuration experienced by customers, who often have no clear knowledge of what solution might correspond to their needs. At times these needs are not even apparent to the customers. As a result, customers may experience uncertainty or even perplexity during the design process". As a matter of fact, the kind of choice offered by online product customization services is usually limited because of two main reasons:

- On the one hand, the configuration of a product from scratch is costly for the firm, because it leads to an excessive amount of variability, and it might generate undesired outcomes spoiling the brand image. For instance, Berger and Piller [28] report that Adidas prevented customers from designing unusual color definitions, and similar considerations may hold for fit and quality aspects of products. 
- On the other hand, this activity might be lengthy and even difficult for the customer, if she does not have the required technical knowledge.

While the former issue can be addressed by introducing hard configuration constraints to reduce the solution space, the latter can be addressed by employing personalization techniques aimed at improving the quality of the interaction with the customer during the configuration process. For instance, the customer could be greatly helped in the design of her products if the configuration system supported the specification of high-level features corresponding to usage requirements; e.g., the reliability, ease of use and robustness of a technological device. In this way, the configuration system would act as an intelligent assistant masking the underlying configuration settings.

The integration of personalization and configuration techniques has been experimented in the CAWICOMS EU project [43] to support the development of useradaptive configuration systems customizing complex technological products and services. As described by Ardissono et al. in [18], in the proposed framework an Intelligent User Interface elicits the customer's functional requirements, which are translated to technical constraints to be solved by a configuration engine. The acquisition of the customer's requirements is carried out in different steps, each one leading to a restriction of the solution space, and the user is prevented from expressing inconsistent preferences because, at each step, the admissible values for the product features are suitably restricted. Starting from the industrial partners' needs, the CAWICOMS framework was exploited to develop a prototype configuration system supporting sales engineers in the online configuration of IP/VPNs. However, the same techniques could be used to support the customization of other products and services, which challenge the customer with complex expertise requirements. For instance, in the configuration of a loan, an automated assistant might guide the customer in the selection of technical features matching family and income constraints, but also features such as the flexibility of payments, risk assessment and so forth.

\section{Context-aware Applications and Ubiquitous Computing}

\subsection{The New Scenario}

Recently, the introduction on the market of mobile devices has lead to the idea of ubiquitous computing, i.e., the possibility of accessing a service anytime, anywhere and by means of different types of (mobile) devices. The services offered should be tailored to the specific context of use, that is particularly significant if the user is mobile, e.g. walking around a city or driving a car. The importance of providing ubiquitous access to integrated services, and the consequent centrality of context modeling and adaptation to context and device, are advocated by many authors, who claim that ubiquitous computing will play a major role in the future of both academia and company research labs; e.g., see [159, 34, 54] and Chapter 17 of this book [94].

This new scenario requires service providers to consider new adaptation features, such as the user's location, her traveling speed, the environment conditions 
(lightness, noise, etc.), and, especially, the characteristics of the increasing variety of mobile devices used to access the services; see [136]. Besides, different interaction conditions must be considered: the mobile user does not usually interact with services for exploration purposes (as sometimes happens in standard Web interaction), but she often has a precise goal, such as finding a specific piece of information. Moreover, she is likely performing other activities in parallel, such as carrying a luggage or listening to the announcement of a train arrival. These situations generate additional constraints that have to be taken into account by ubiquitous systems; see, for instance, [159, 72, 96].

The number of applications which may be classified as context-aware is very large and their presentation would lead our discussion out of the scope of this chapter. ${ }^{7}$ However, we think that the most important aspect of context-aware applications is the possibility to integrate different adaptation strategies, in order to consider the user's interests and needs, as well as context conditions and device specific requirements (e.g., bandwidth and screen size). With respect to this issue, mobile guides represent an excellent example of how adaptation can support the provision of ubiquitous services; see [93] and Chapter 17 of this book [94]. Since the first example of a mobile guide, Cyberguide [1], many research prototypes (e.g., $[155,126,9,45,127,100,26])$, and commercial systems (e.g., $[63,151])$ have been developed. While car manufacturers offer more or less sophisticated on-board navigation systems, ${ }^{8}$ research prototypes aim at offering ubiquitous services based on the integration of different adaptation strategies enabled by heterogeneous technologies.

\subsection{M-Commerce}

Ubiquitous computing poses new challenges to e-commerce, as well. Recently, the term $m$-commerce has been introduced to refer to commercial transactions performed by using wireless devices; e.g., [51, 153, 154]. However, m-commerce has evolved differently from traditional e-commerce; for instance, Stafford and Gillenson [144] point out that, while the latter is mainly focused on supporting commercial transactions, the former is more oriented towards offering an enhanced information access. The authors highlight that this change could be due to the flop of the WAP protocol, that was explicitly designed to support transactions on wireless networks; after the WAP failure, mobile devices gained a new role, by supporting product information provision instead of business transactions. For example, the authors report that in Japan there is a common practice, according to which customers retrieve information about shopping choices by using iMode phones, but they place orders within in-store self-service kiosks. In this perspective, m-commerce can be viewed as a support for actual e-commerce transactions, providing information and promotion. Other possible exploitations of mobile devices to support e-commerce activities are digi-

\footnotetext{
${ }^{7}$ Chen and Kotz [44] provide an interesting survey of context-aware applications, and Dourish [57] discusses the concept of context from different perspectives.

${ }^{8}$ A query on www.globalsources.com lists more than one hundred products under the category "Car Navigation System".
} 
tal wallets, push information services, and location-based services, like automatic updates of travel reservations, and up-to-date information about on going events.

As discussed in [145], the most innovative aspect of m-commerce is the possibility to utilize information about the user's local context to tailor offers and suggestions. The information about the user's location, for instance, can be useful to provide timely, relevant, and focused services. Moreover, her location provides rough information about the physical context and the type of activity she is involved in; for example, the user might be visiting a museum, or attending a concert, or driving on a highway. Rao and Minakakis [129] list various business opportunities for locationbased services, ranging from adaptive maps and driving directions to the automatic tracking of material, people, or products along the supply chain. Moreover, in Chapter 17 of this book [94], Krüger et al. describe several mobile applications supporting the user during her shopping activity. Those applications are good examples of context-aware, ubiquitous services, providing the customer with information about products, guiding her around the (physical) store, suggesting personalized shopping lists, and so forth.

Given all these opportunities, at the very beginning of the new millennium, many researchers, service providers and mobile device vendors, had foreseen a great expansion of $\mathrm{m}$-commerce, thinking that it would have soon been the main business $[59,141]$. However, the expansion of $\mathrm{m}$-commerce has been much slower than expected, and the enthusiasm had to be put in perspective. There are various reasons for this mismatch between expectations and reality. In the first place, mobile devices are not very usable and they are still limited in processing power, bandwidth and computational efficiency, I/O capabilities, etc., coupling high service costs with poor quality of service. Moreover, the lack of standards and shared protocols represents a serious obstacle to the provision of truly ubiquitous services. All these reasons together made the acceptance of mobile devices very low. Sarker and Wells [137] list several factors that influence the adoption of mobile devices, and thus the fruition of ubiquitous services, ranging from individual attitudes to cultural context, from the quality of the technological support to the user's goals. However, according to the authors, the key factor is that, taking all these aspects into account, the use process must result in a positive experience for the user.

\subsection{Future Perspectives}

From these considerations, it is clear that the ubiquitous/mobile access to services poses new challenges to the design and development of e-commerce systems, and, in particular, usability seems to be a key factor for its success. In fact, the traditional user interfaces design methods, developed for desktop computers, cannot be applied as they are to the development of user interfaces for mobile devices. New design methods are required $[62,156,96]$ and adaptation techniques are widely recognized as key tools to handle the interaction in mobile user interfaces and to enhance the usability of mobile and wireless services; see, e.g., [30, 143, 37, 72]. In this perspective, new features become relevant for the usability, ad henceforth for the adaptation; for instance, the physical location of the user, but also environment conditions like 
noise, lightness, whether she is driving or walking, and the characteristics of the device she is using, as claimed, e.g., by Wahlster [159] and Hinz et al. [74], among the others.

An important form of adaptation is the generation of product and service presentations whose length is tailored to the screen size. Many systems adapt the quantity of information presented to the size of the screen. For instance, the UbiquiTO system [9] presents items at different levels of detail on the basis of the screen size and of the user's interests; to this purpose, the system applies adaptation rules which support the selection of one out of four pre-stored versions of the item descriptions (long-essential, long-detailed, short-essential and short-detailed).

However, the most important feature for context-aware applications is the adaptation of the layout of the user interface to the characteristics of the device used to access the service. This adaptation form can be implemented following two approaches [74]:

- The first one aims at adjusting existing (HTML) Web pages to the requirements of mobile devices. In this approach, the limitations imposed by display size and interaction capabilities are taken into account; e.g. [99].

- The second approach is based on an abstract, device-independent definition of the content of the user interface (usually based on XML), which can be used to dynamically generate different instances of the user interface, tailored to the device features and constraints.

The former approach has the advantage that it can be applied to already existing Web resources, but the latter is more flexible and extensible; for instance, new rules for generating user interfaces for new types of devices can be easily added. The automatic generation of alternative layouts starting from an abstract definition of the user interface has been addressed in several projects; e.g., [55, 118, 52, 109, 9, 71]. A standard approach is based on the application of XSL stylesheets that transform an XML object into the object representing the actual user interface (HTML, XHTML, CHTML, WML, Voice-XML, etc.), by taking the characteristics of the devices and, possibly, other context features into account. For example, in a dark place voice output is preferred to written text, but the opposite preference holds in a noisy place.

\section{Discussion}

This chapter has offered an overview of the techniques developed both at the research level and in commercial settings to support personalization in B2C e-commerce applications. In this overview, we have focused on the techniques applied in Web stores and electronic catalogs, which are nowadays used by millions of customers. Moreover, we have analyzed the provision of personalized services customizing the definition of Service Level Agreements; that application scenario poses interesting challenges because it requires the integration of personalization and configuration techniques to support a user friendly interaction with the customer during the negotiation of the service to be defined. 
B2C e-commerce is the area where personalization techniques have been most frequently applied. However, before closing this chapter, we would like to shortly discuss the potential of personalization in a in B2B e-commerce context, where we believe that personalization may play a key role in dynamic supply chain management. Usually, service providers rely on alternative suppliers, which may offer similar services but at different costs and supporting different Quality of Service (QoS) levels. When a customer requests a service, the appropriate providers should be selected, in order to offer a service matching functional and QoS requirements. We identify two main issues:

- Service Discovery: this issue concerns the dynamic selection and composition of services satisfying the customer's needs and preferences.

- Logic interoperability between service providers. This second issue concerns the adaptation to diverse business strategies during the interaction with suppliers and includes adapting to the requirements of business partners, such as QoS levels, business protocols, and similar.

Within this scenario, the new paradigm of Web Services comes into play. Web Services are distributed software modules, wrapped by standard communication interfaces enabling them to interoperate with each other.

1. The first phase of Web Service interaction is the discovery of the service fulfilling the consumer requirements. In Enterprise Application Integration, this phase is trivial because all the available services are known. However, in an open environment, such as the Web, the discovery phase can be critical because it requires advanced match-matching techniques.

2. After discovery, in many cases the services need to be integrated in order to offer a composite service, made up of several, simpler ones, possibly organized within a workflow (Web Service composition).

3. Finally, the last phase is the execution of the selected service, that implies an interaction between the Web Service provider and its consumer. This type of interaction can be as simple as a request/response exchange, but in several cases can have a complex structure, which can be modeled as a conversation.

In the Service Oriented Computing research [117], Web Services description languages, such as WSDL [157], enable the specification of service public interfaces. Moreover, Web Service orchestration languages, such as WS-BPEL [12, 112], support the definition of composite services based on the orchestration of multiple providers within possibly complex workflows.

Although some proposals have been presented to address the service discovery and logic interoperability issues mentioned above, it is fair to say that personalization has not attracted yet the attention of Web Service application developers, who are focused on other, primary issues, such as security and trust management, and low-level interoperability enablement. In fact, the first goal to be achieved is to abstract service management from the details of the deployment environment of the applications, and to support a seamless interaction between the possibly heterogeneous Enterprise Resource Management software employed by the various partners. For this reason, 
Web Services are currently mainly intended for B2B integration, but we can foresee that networked services will probably move soon into the area of B2C interactions. With the number of services and also their diversity expected to grow, adequate techniques for user-centric and preference-based service discovery and selection will be needed. Even though UDDI ${ }^{9}$ and WSDL are standards today to implement service catalogs, they still lack concepts for service personalization; the work by McIlraith et al. [106] and by Sycara et al. [147] are examples of research in this area. Considering the interaction with a user-centered, personalized service, all of the three discovery, composition and execution phases may be enhanced by personalization, but in particular the service discovery and composition. Semantic Web techniques have been used to improve standard Web Service languages in order to add information used in personalization; see, e.g., [106, 101]. Moreover, some attempts to conform to the customer's preferences in the selection of suitable service providers have been done in the work by Balke and Wagner [24, 25]. At the same time, research in the design of composite Web Services has started. The creation of complex e-services requires innovative approaches to the design process, in order to guarantee the service quality; in particular the service must be reliable and available, and it must comply to quality dimensions, such as QoS, temporal constraints, stability, etc.; e.g., see [42].

As a last consideration, we would like to remark that, regardless of the scenario to which it may be applied (e.g., B2B or B2C), personalization is not a value per se. As discussed in the previous sections, a Web site tailoring the interaction to the individual user, or customizing products and services on an individual basis, is not necessary better than a Web site offering standard solutions. In other words, personalization should not be considered as a goal, but as a mean providing the company and the customers with some advantages. Indeed, the personalization can be considered as an added value only if it represents an advantage in terms of:

- CRM: i.e., if it supports long-term relationships between the company and its customers, increasing customer loyalty;

- Quality of the offer: e.g., the products and services are tailored to individual customer needs;

- Usability of the Web site: i.e., if the personalization of the interaction makes it easier for the user to navigate the e-commerce site;

- Backoffice integration: e.g., if the personalization supports flexible interoperability between suppliers.

Many researchers who design and develop personalized e-commerce systems seem to forget that the added value of personalization is not given a-priori, but must be demonstrated within the context of any specific application. For this reason, testing personalized e-commerce systems with real users is of paramount importance; see, e.g., the discussion in [82], [46] and in Chapter 24 of this book [67].

\footnotetext{
${ }^{9}$ The current basic standard for service discovery. See www.uddi.org/
} 


\section{References}

1. Abowd, D.A., Atkeson, C.G., Hong, J., Long, S., Pinkerton, M.: Cyberguide: a mobile context-aware tour guide. Wireless Networks 3(5) (1996) 421-433

2. Abowd, G., Mynatt, E.: Charting past, present and future research in ubiquitous computing. ACM Transactions on Computer-Human Interaction, Special Issue on HCI in the new Millennium 7(1) (2000) 29-58

3. Adidas: mi adidas - customised shoes for you, http://www.adidas.com/products/miadidas04/content/UK/container.asp (2005)

4. Agrawal, R., Mannila, H., Srikant, R., Toivonen, H., Verkamo, A.: Fast discovery of association rules. Advances in Knowledge Discovery and Data Mining. AAAI/MIT Press, Cambridge, MA (1995)

5. Alani, H., Kim, S., Millard, D., Weal, M., Hall, W., Lewis, P., Shadbolt, N.: Automatic ontology-based knowledge extraction from Web documents. IEEE Intelligent Systems 18(1) (2003) 14-21

6. Alani, H., Kim, S., Millard, D., Weal, M., Hall, W., Lewis, P., Shadbolt, N.: Using Protégé for automatic ontology instantiation. In: Proc. of 7th Int. Protégé Conf., Bethesda, Maryland (2004)

7. Alpert, S., Karat, J., Karat, C., Brodie, C., Vergo, J.: User attitudes regarding a useradaptive eCommerce Web Site. User Modeling and User-Adapted Interaction 13(4) (2003) 373-396

8. Amazon.com: Amazon.com: online shopping for electronics, apparel, etc., http://www.amazon.com (2006)

9. Amendola, I., Cena, F., Console, L., Crevola, A., Gena, C., Goy, A., Modeo, S., Perrero, M., Torre, I., Toso, A.: UbiquiTO: a multi-device adaptive guide. In Brewster, S., Dunlop, M. (eds.): LNCS 3160, Mobile Human-Computer Interaction (Mobile HCI 2004). Springer-Verlag, Berlin Heidelberg New York (2004) 409-114

10. ameris: Glossary of IT \& internet terms, http://www.ekeda.com/glossary_of_terms.cfm (2005)

11. André, E., Rist, T.: Presenting through performing: on the use of multiple lifelike characters in knowledge-based presentation systems. In: Proc. 2000 Int. Conf. on Intelligent User Interfaces (IUI'00), New Orleans, Louisiana, ACM Press (2000) 1-8

12. Andrews, T., Curbera, F., Dholakia, H., Goland, Y., Klein, J., Leymann, F., Liu, K., Roller, D., Smith, D., Trickovic, S.T.I., Weerawarana, S.: Business Process Execution Language for Web Services version 1.1, http://www106.ibm.com/developerworks/webservices/library/ws-bpel/ (2003)

13. Arden, R.: Safe internet shopping with Microsoft Merchant System, http://www.windowsitpro.com/Windows/Article/ArticleID/2799/2799.html (2005)

14. Ardissono, L., Botta, M., Costa, L.D., Petrone, G., Bellifemine, F., Difino, A., Negro, B.: Customer information sharing between e-commerce applications. In: Proc. WOA 2004 - Sistemi Complessi e Agenti Razionali, Torino, Italy (2004)

15. Ardissono, L., Gena, C., Torasso, P., Bellifemine, F., Difino, A., Negro, B.: User modeling and recommendation techniques for personalized Electronic Program Guides. In: Personalized Digital Television. Targeting Programs to Individual Users. Kluwer Academic Publishers (2004)

16. Ardissono, L., Goy, A.: Dynamic generation of adaptive Web catalogs. In Brusilovsky, P., Stock, O., Strapparava, C. (eds.): LNCS n. 1892: Adaptive Hypermedia and Adaptive Web-Based Systems, Int. Conference (AH 2000). Springer-Verlag, Berlin Heildelberg New York (2000) 5-16 
17. Ardissono, L., Goy, A.: Tailoring the interaction with users in Web stores. User Modeling and User-Adapted Interaction 10(4) (2000) 251-303

18. Ardissono, L., Goy, A., Petrone, G., Felfernig, A., Friedrich, G., Jannach, D., Zanker, M., Schaefer, R.: A framework for the development of personalized, distributed Webbased configuration systems. AI Magazine 24(3) (2003) 93-110

19. Ardissono, L., Goy, A., Petrone, G., Segnan, M.: Personalization in Business-toConsumer interaction. Communications of the ACM, Special Issue "The Adaptive Web" 45(5) (2002) 52-53

20. Ardissono, L., Goy, A., Petrone, G., Segnan, M., Torasso, P.: INTRIGUE: personalized recommendation of tourist attractions for desktop and handset devices. Applied Artificial Intelligence, Special Issue on Artificial Intelligence for Cultural Heritage and Digital Libraries 17(8-9) (2003) 687-714

21. Avery, C., Resnick, P., Zeckhauser, R.: The market for evaluations. American Economic Review 89(3) (1999) 564-584

22. Bae, S., Park, S., Ha, S.: Fuzzy Web ad selector based on Web usage mining.

23. Balabanovic̀, M., Shoham, Y.: Content-based, collaborative recommendation. Communications of the ACM 40(3) (1997)

24. Balke, W., Wagner, M.: Towards personalized selection of Web Services. In: Proc. of 12th Int. World Wide Web Conference (WWW'2003), Budapest (2003)

25. Balke, W., Wagner, M.: Through different eyes - assessing multiple conceptual views for querying Web Services. In: Proc. of 13th Int. World Wide Web Conference (WWW'2004), New York (2004)

26. Baus, J., Kray, C., Krüger, A.: Visualization of route descriptions in a resource-adaptive navigation aid. Cognitive Processing 2(2-3) (2001) 323-345

27. Benyon, D.: Adaptive systems: a solution to usability problems. User Modeling and User-Adapted Interaction 3 (1993) 65-87

28. Berger, C., Piller, F.: Customers as co-designers. IEE Manufacturing Engineer ( $\mathrm{Au}-$ gust/September) (2003) 42-45

29. Bertini, E., Kimani, S.: Mobile devices: opportunities for users with special needs. In Chittaro, L., ed.: LNCS 2795, Human Computer Interaction with Mobile Devices and Services, 5th Int. Symposium Mobile HCI 2003. Springer-Verlag, Berlin Heidelberg New York (2003) 486-491 IEEE Intelligent Systems 18(6) (2003) 62-69

30. Billsus, D., Brunk, C., Evans, C., Gladish, B., Pazzani, M.: Adaptive interfaces for ubiquitous Web access. Communications of the ACM, Special Issue on The Adaptive Web 45(5) (2002) 34-38

31. Billsus, D., Pazzani, M.: A personal news agent that talks, learns and explains. In: Proc. 3rd Int. Conf. on Autonomous Agents (Agents '99), Seattle, WA (1999) 268-275

32. Blom, J., Monk, A.: One-to-one e-commerce: who's the one? In: Proc. of Conf. on Human Factors in Computing Systems (CHI'01), Seattle, WA, ACM Press (2001) 341342

33. Blue Martini Retail: Sell more proactively. Blue Martini Software (2006)

34. Borriello, G., Chalmers, M., Marca, A.L., Nixon, P.: Delivering real-world ubiquitous location systems. Communications of the ACM, Special Issue on The Disappearing Computer 48(3) (2005) 36-41

35. BroadVision: BROADVISION, http://www.broadvision.com/ (2005)

36. Brusilovsky, P.: Methods and techniques of Adaptive Hypermedia. User Modeling and User-Adapted Interaction 6(2-3) (1996) 87-129

37. Brusilovsky, P.: Adaptive Hypermedia. User Modeling and User-Adapted Interaction 11(1-2) (2001) 87-110 
38. Bunt, A., Carenini, G., Conati, C.: Adaptive content presentation for the Web. In Brusilovsky, P., Kobsa, A., Nejdl, W. (eds.): The Adaptive Web: Methods and Strategies of Web Personalization, Lecture Notes in Computer Science, Vol. 4321. SpringerVerlag, Berlin Heidelberg New York (2006) this volume

39. Burke, R.: Hybrid recommender systems: survey and experiments. User Modeling and User-Adapted Interaction 12(4) (2002) 289-322

40. Burke, R.: Hybrid Web recommender systems. In Brusilovsky, P., Kobsa, A., Nejdl, W. (eds.): The Adaptive Web: Methods and Strategies of Web Personalization, Lecture Notes in Computer Science, Vol. 4321. Springer-Verlag, Berlin Heidelberg New York (2006) this volume

41. Butler, P., Cales, R., Petersen, J., Banick, S., Denschikoff, C., McPherson, S., Melnick, D.: Using Microsoft Commercial Internet System, http://docs.rinet.ru/MCIS/ (2005)

42. Cappiello, C., Pernici, B., Plebani, P.: Quality-agnostic or quality-aware semantic service descriptions? In: Proc. W3C Workshop on Frameworks for Semantics in Web Services, Innsbruck, Austria (2005)

43. CAWICOMS: Customer-Adaptive Web Interface for the COnfiguration of products and services with Multiple Suppliers, http://www.cawicoms.org (2001)

44. Chen, G., Kotz, D.: A Survey of Context-Aware Mobile Computing Research, Technical Report: TR2000-381. PhD thesis, Dartmouth College, Hanover, NH, USA (2000)

45. Cheverst, K., Davies, N., Mitchell, K., Smith, P.: Providing tailored (context-aware) information to city visitors. In Brusilovsky, P., Stock, O., Strapparava, C. (eds.): LNCS n. 1892: Adaptive Hypermedia and Adaptive Web-Based Systems, Int. Conference (AH 2000), Berlin Heidelberg New York (2000) 73-85

46. Chin, D.: Empirical evaluation of user models and user-adapted systems. User Modeling and User-Adapted Interaction 11(1-2) (2001) 181-194

47. Chittaro, L., Ranon, R.: New directions for the design of virtual reality interfaces to e-commerce sites. In: Proc. Int. Working Conf. on Advanced Visual Interfaces (AVI 2002), Trento, Italy (2002) 308-315

48. Chittaro, L., Ranon, R.: Adaptive 3D Web sites. In Brusilovsky, P., Kobsa, A., Nejdl, W. (eds.): The Adaptive Web: Methods and Strategies of Web Personalization, Lecture Notes in Computer Science, Vol. 4321. Springer-Verlag, Berlin Heidelberg New York (2006) this volume

49. ChoiceStream, Inc.: Choicestream personalization survey. Research brief (2005)

50. Ciravegna, F., Lavelli, L.: LearningPinocchio: Adaptive information extraction for real world applications. Journal of Natural Language Engineering 10(2) (2004)

51. Clarke, I.: Emerging value propositions for $\mathrm{m}$-commerce. Journal of Business Strategies 318(2) (2001) 133-148

52. Coninx, K., Luyten, K., Vandervelpen, C., den Bergh, J.V., Creemers, B.: Dygimes: dynamically generating interfaces for mobile computing devices and embedded systems. In Chittaro, L., ed.: LNCS 2795, Human Computer Interaction with Mobile Devices and Services, 5th Int. Symposium Mobile HCI 2003. Springer-Verlag, Berlin Heidelberg New York (2003) 61-70

53. Corrigan, D.: Achieving advantage with operational customer data integration and management. Data integration solutions (2006)

54. Coutaz, J., Crowley, J., Dobson, S., Garlan, D.: Context is key. Communications of the ACM, Special Issue on The Disappearing Computer 48(3) (2005) 49-53

55. Dees, W.: Device independent user interfaces. In: Proc. of 12th Int. World Wide Web Conference (WWW'2003), Budapest (2003) 209-249 
56. Dey, A., Abowd, D.: Towards a better understanding of context and context-awareness. In: Proc. CHI2000 Workshop on the What, Who, Where, When and How of ContextAwareness, The Hague, Netherlands (2000)

57. Dourish, P.: What we talk about when we talk about context. Personal and Ubiquitous Computing 8(1) (2004) 19-30

58. ebay: The world's online marketplace, http://www.ebay.com (2006)

59. Feldman, S.: Delivering real-world ubiquitous location systems. IEEE Internet Computing 4(6) (2000) 74-75

60. Fink, J., Kobsa, A.: A review and analysis of commercial user modeling servers for personalization on the World Wide Web. User Modeling and User-Adapted Interaction, Special Issue on Deployed User Modeling 10(2-3) (2000) 209-249

61. Fink, J., Kobsa, A., Nill, A.: Adaptable and adaptive information access for all users, including disabled and the elderly. In: Proc. 6th Conf. on User Modeling, Chia Laguna, Italy (1997) 171-173

62. Fithian, R., Iachello, G., Moghazy, J., Pousman, Z., Stasko, J.: The design and evaluation of mobile location-aware handheld event planner. In Chittaro, L., ed.: LNCS 2795, Human Computer Interaction with Mobile Devices and Services, 5th Int. Symposium Mobile HCI 2003, Berlin Heidelberg New York, Springer-Verlag (2003) 145-160

63. Garmin Ltd.: Streetpilot 2650, http://www.garmin.com/products/spIII (2003)

64. Gaudin, S.: Study: personalization not secret to e-commerce. DATAMATION - EARTHWEB (2003)

65. Geller, M., Bruner, R.: Interactive marketing and consumer packaged goods. In search of CPG marketing gold. DoubleClick email solutions (2005)

66. Gena, C.: Evaluation methodologies and user involvement in user modeling and adaptive systems. PhD thesis, University of Torino (2002)

67. Gena, C., Weibelzahl, S.: Usability engineering for the Adaptive Web. In Brusilovsky, P., Kobsa, A., Nejdl, W. (eds.): The Adaptive Web: Methods and Strategies of Web Personalization, Lecture Notes in Computer Science, Vol. 4321. Springer-Verlag, Berlin Heidelberg New York (2006) this volume

68. Gilmore, J., Pine, B.: The four faces of mass customization. Harvard Business Review 75(January-February) (1997) 91-101

69. Greco, S.: The road to one-to-one marketing. In: Inc. Magazine, http://www.inc.com/magazine/19951001/2433.html (1997)

70. Hall, C.: Business intelligence - the personalization equation. Software Magazine (April) (2001)

71. Healey, J., Hosn, R., Maes, S.H.: Adaptive content for device independent multi-modal browser applications. In Brewster, S., Dunlop, M. (eds.): LNCS 3160, Mobile HumanComputer Interaction (Mobile HCI 2004). Springer-Verlag, Berlin Heidelberg New York (2004) 401-105

72. Herder, E., van Dijk, B.: Personalized adaptation to device characteristics. In De Bra, P., Brusilovsky, P., Conejo, R. (eds.): LNCS 2347, Adaptive Hypermedia and Adaptive Web Based Systems, Second Int. Conference (AH 2002), Berlin Heidelberg New York, Springer-Verlag (2002) 598-602

73. Herlocker, J., Konstan, J., Riedl, J.: Explaining collaborative filtering recommendations. In: Proc. ACM 2000 Conf. on Computer Supported Cooperative Work, Philadelphia, PA (2000)

74. Hinz, M., Fiala, Z., Wehner, F.: Personalization-based optimization of Web interfaces for mobile devices. In Brewster, S., Dunlop, M. (eds.): LNCS 3160, Mobile HumanComputer Interaction (Mobile HCI 2004). Springer-Verlag, Berlin Heidelberg New York (2004) 204-215 
75. IBM: IBM WebSphere Commerce - xpress edition, http://www306.ibm.com/software/websphere/sw-bycategory/subcategory/SWH00.html (2005)

76. IBM: WebSphere software - business integration solutions, http://www306.ibm.com/software/websphere/ (2005)

77. ILOG: ILOG JConfigurator, http://www.ilog.com/products/jconfigurator/ (2002)

78. Jameson, A., Schäfer, R., Simons, J., Weis, T.: Adaptive provision of evaluation-oriented information: tasks and techniques. In: Proc. 14th IJCAI, Montreal (1995) 1886-1893

79. Jameson, A., Smyth, B.: Recommending to groups. In Brusilovsky, P., Kobsa, A., Nejdl, W. (eds.): The Adaptive Web: Methods and Strategies of Web Personalization, Lecture Notes in Computer Science, Vol. 4321. Springer-Verlag, Berlin Heidelberg New York (2006) this volume

80. JBoss, the Professional Open Source Company: JBoss Application Server, http://www.jboss.org/products/jbossas (2005)

81. Jupiter Research: Beyond the personalization myth. Site Technologies \& Operations (2003)

82. Karat, C., Brodie, C., Karat, J., Vergo, J., Alpert, S.: Personalizing the user experience on ibm.com. IBM Systems Journal 42(4) (2003) 686-701

83. Kay, J., Kummerfeld, B., Lauder, P.: Personis: a server for user models. In De Bra, P., Brusilovsky, P., Conejo, R. (eds.): LNCS 2347, Adaptive Hypermedia and Adaptive Web Based Systems, Second Int. Conference (AH 2002), Berlin Heidelberg New York, Springer-Verlag (2002) 203-212

84. Kazienko, P., Adamski, M.: Personalized Web advertising method. In De Bra, P., Nejdl, W. (eds.): LNCS 3137, Adaptive Hypermedia and Adaptive Web-Based Systems, 3rd Int. Conference, AH2004. Springer-Verlag, Berlin Heidelberg New York (2004) 146155

85. Kelly, S.: Data warehousing: the route to mass customization. Wiley, New York, NY (1996)

86. Kinsgstone, S.: Balancing cost reduction with value generation when delivering customer-centric services. Customer-Centric Strategies (2005)

87. Kobsa, A.: Generic user modeling systems. User Modeling and User-Adapted Interaction, Ten Year Anniversary Issue (2000)

88. Kobsa, A.: Personalized hypermedia and international privacy. Communication of the ACM 45(5) (2002) 64-67

89. Kobsa, A.: Generic user modeling systems. In Brusilovsky, P., Kobsa, A., Nejdl, W. (eds.): The Adaptive Web: Methods and Strategies of Web Personalization, Lecture Notes in Computer Science, Vol. 4321. Springer-Verlag, Berlin Heidelberg New York (2006) this volume

90. Kobsa, A.: Privacy-enhanced Web personalization. In Brusilovsky, P., Kobsa, A., Nejdl, W. (eds.): The Adaptive Web: Methods and Strategies of Web Personalization, Lecture Notes in Computer Science, Vol. 4321. Springer-Verlag, Berlin Heidelberg New York (2006) this volume

91. Kobsa, A., Koenemann, J., Pohl, W.: Personalized hypermedia presentation techniques for improving online customer relationships. The Knowledge Engineering Review 16(2) (2001) 111-155

92. Kobsa, A., Schreck, J.: Privacy through pseudonymity in user-adaptive systems. ACM Transactions on Internet Technology 3(2) (2002) 149-183

93. Kray, C., Baus, J.: A survey of mobile guides. In: Proc. HCI Workshop on mobile guides, at Mobile HCI 2004, Udine, Italy (2004) 
94. Krüger, A., Baus, J., Heckmann, D., Kruppa, M., Wasinger, R.: Web-based mobile guides. In Brusilovsky, P., Kobsa, A., Nejdl, W. (eds.): The Adaptive Web: Methods and Strategies of Web Personalization, Lecture Notes in Computer Science, Vol. 4321. Springer-Verlag, Berlin Heidelberg New York (2006) this volume

95. Langheinrich, M., Nakamura, A., Abe, N., Kamba, T., Koseki, Y.: Unintrusive customization techniques for Web advertising. Computer Networks 31(11-16) (1999) $1259-1272$

96. Lee, Y.E., Benbasat, I.: Interface design for mobile commerce. Communications of the ACM 46(12) (2003) 49-52

97. Liberty Alliance Developer Forum: Liberty alliance project specifications, http://www.projectliberty.org/specs/ (2004)

98. Linden, G., Smith, B., York, J.: Amazon.com recommendations - item-to-item collaborative filtering. IEEE Internet Computing (January-February) (2003) 76-80

99. MacKay, B., Watters, C., Duffy, J.: Web page transformation when switching devices. In Brewster, S., Dunlop, M. (eds.): LNCS 3160, Mobile Human-Computer Interaction (Mobile HCI 2004). Springer-Verlag, Berlin Heidelberg New York (2004) 228-239

100. Malaka, R., Zipf, A.: DEEP MAP - challenging IT research in the framework of a tourist information system. In: Proc. ENTER 2000, Information and Communication Technologies in Tourism, Barcelona, Spain, Springer-Verlag (2000) 15-27

101. Mandell, D.J., McIlraith, S.A.: Adapting BPEL4WS for the Semantic Web: The bottomup approach to Web Service interoperation. In: LNCS 2870, Proc. 2nd International Semantic Web Conf. (ISWC 2003). Springer-Verlag, Sanibel Island, Florida (2003) 227-241

102. Marcias, M., Gonzalez, J., Sanchez, F.: On adaptability of Web sites for visually handicapped people. In De Bra, P., Brusilovsky, P., Conejo, R. (eds.): LNCS 2347, Adaptive Hypermedia and Adaptive Web Based Systems, Second Int. Conference (AH 2002). Springer-Verlag, Berlin Heidelberg New York (2002) 264-273

103. Masthoff, J.: Group modeling: Selecting a sequence of television items to suit a group of viewers. User Modeling and User-Adapted Interaction 14(1) (2004) 37-85

104. Maybury, M., Brusilovsky, P. (eds.): The adaptive Web. Volume 45. Communications of the ACM (2002)

105. McCarthy, K., Reilly, J., McGinty, L., Smyth, B.: On the dynamic generation of compound critiques in conversational recommender systems. In De Bra, P., Nejdl, W. (eds.): LNCS 3137, Adaptive Hypermedia and Adaptive Web-Based Systems, 3rd Int. Conference, AH2004. Springer-Verlag, Berlin Heidelberg New York (2004) 176-184

106. McIlraith, S., Son, T., Zeng, H.: Semantic Web Services. IEEE Intelligent Systems 16(2) (2001) 46-53

107. McKeown, K.: Discourse strategies for generating natural-language text. Artificial Intelligence 27 (1985) 1-41

108. Milosavljevic, M.: The automatic generation of comparison in descriptions of entities. $\mathrm{PhD}$ thesis, Macquarie University, Sydney (1999)

109. Mori, G., Paternò, F., Santoro, C.: Tool support for designing nomadic applications. In: Proc. 8th Int. Conf. on Intelligent User Interfaces (IUI’03), Miami Beach, Florida, ACM Press (2003) 141-148

110. Ndiaye, A., Jameson, A.: Predictive role taking in dialog: global anticipation feedback based on transmutability. In: Proc. 5th Int. Conf. on User Modeling, Kailua-Kona, Hawaii (1996) 137-144

111. Netscape: Netscape MerchantXpert, http://wp.netscape.com/merchantxpert/index.html (2005) 
112. OASIS: OASIS Web Services Business Process Execution Language, http://www.oasisopen.org/committees/documents.php?wg_abbrev=wsbpel (2005)

113. Omelayenko, B.: Learning of ontologies from the Web: the analysis of existent approaches. In: Int. ICDT'01 Workshop on Web Dynamics, London, UK (2001)

114. Opperman, R.: Adaptive user support - Ergonomic design of manually and automatically adaptable software. Lawrence Erlbaum Associates, Hillsdale, NJ (1994)

115. Oracle: Oracle Application Server, http://www.oracle.com/appserver/index.html (2005)

116. O' Sullivan, D., Smyth, B., Wilson, D., Donald, K.M., Smeaton, A.: Interactive television personalisation. From guides to programmes. In Ardissono, L., Maybury, M., Kobsa, A. (eds.): Personalized Digital Television. Targeting programs to individual users. Kluwer, Dordrecht (2004) 73-92

117. Papazoglou, M., Georgakopoulos, D.: Service-Oriented Computing. Communications of the ACM 46(10) (2003)

118. Pashtan, A., Kollipara, S., Pearce, M.: Adapting content for wireless Web Services. IEEE Internet Computing 7(1) (2003) 74-78

119. Pazzani, M., Billsus, D.: Content-based recommendation systems. In Brusilovsky, P., Kobsa, A., Nejdl, W. (eds.): The Adaptive Web: Methods and Strategies of Web Personalization, Lecture Notes in Computer Science, Vol. 4321. Springer-Verlag, Berlin Heidelberg New York (2006) this volume

120. Peppers, D., Rogers, M.: The one to one future: building relationships one customer at a time. Currency Doubleday, New York, NY (1993)

121. Peppers, D., Rogers, M.: Enterprise one to one. Currency Doubleday, New York, NY (1997)

122. Pierrakos, D., Paliouras, G., Papatheodorou, C., Spyropoulos, C.: Web usage mining as a tool for personalization: a survey. User Modeling and User-Adapted Interaction 13(4) (2003) 311-372

123. Piller, F., Müller, M.: A new marketing approach to mass customisation. Int. Journal of Computer Integrated Manufacturing 17(7) (2004) 583-593

124. Pine, B., Gilmore, J.: The experience economy. Harvard Business School Press, Boston, MA (1999)

125. Popp, H., Lödel, D.: Fuzzy techniques and user modeling in sales assistants. User Modeling and User-Adapted Interaction 6 (1996) 349-370

126. Poslad, S., Laamanen, H., Malaka, R., Nick, A., Buckleand, P., Zipf, A.: CRUMPET: CReation of User-friendly Mobile services PErsonalised for Tourism. In: Proc. 3G2001 Mobile Communication Technologies, London, UK (2001) 28-32

127. Pospischil, G., Umlauft, M., Michlmayr, E.: Designing lol@, a mobile tourist guide for UMTS. In Paterno, F., ed.: LNCS 2411, Human Computer Interaction with Mobile Devices and Services, 4th Int. Symposium Mobile HCI 2002. Springer-Verlag, Berlin Heidelberg New York (2002) 140-154

128. Pu, P., Faltings, B., Torrens, M.: Effective interaction principles for online product search environments. In: Proc. IEEE/WIC/ACM Int. Joint Conf. on Intelligent Agent Technology and Web Intelligence, Beijing, China (2004) 724-727

129. Rao, B., Minakakis, L.: Evolution of mobile location-based services. Communications of the ACM 46(12) (2003) 61-65

130. Reichheld, F.: The loyalty effect. Harvard Business School Press, Boston, MA (1996)

131. Resnick, P., Varian, H. (eds.): Special Issue on Recommender Systems. Volume 40. Communications of the ACM (1997)

132. Rich, E.: Stereotypes and user modeling. In Kobsa, A., Wahlster, W. (eds.): User Models in Dialog Systems. Springer-Verlag, Berlin (1989) 35-51 
133. Richter, K., Enge, M.: Multi-modal framework to support users with special needs in interaction with public information systems. In Chittaro, L., ed.: LNCS 2795, Human Computer Interaction with Mobile Devices and Services, 5th Int. Symposium Mobile HCI 2003. Springer-Verlag, Berlin Heidelberg New York (2003) 286-301

134. Rutledge, P.: Let's get personal: enhancing the customer experience with Web personalization. Patrice-Anne Rutledge (2003)

135. Sacco, G.: Dynamic taxonomies: a model for large information bases. IEEE Trans. on Knowledge and Data Engineering 12(3) (2000) 468-479

136. Sadeh, N.: Mobile commerce: new technologies, services and business models. Wiley \& Sons, Ltd. (2002)

137. Sarker, S., Wells, J.D.: Understanding mobile handheld device use and adoption. Communications of the ACM 46(12) (2003) 35-40

138. Sarwar, B., Karypis, G., Konstan, J., Riedl, J.: Item-based collaborative filtering recommendation algorithms. In: Proc. of 10th Int. World Wide Web Conference (WWW'2001), Hong Kong (2001)

139. Schafer, J., Frankowski, D., Herlocker, J., Sen, S.: Collaborative filtering recommender systems. In Brusilovsky, P., Kobsa, A., Nejdl, W. (eds.): The Adaptive Web: Methods and Strategies of Web Personalization, Lecture Notes in Computer Science, Vol. 4321. Springer-Verlag, Berlin Heidelberg New York (2006) this volume

140. Schafer, J., Konstan, J., Riedl, J.: Recommender systems in e-commerce. In: Proc. of the ACM Conference on Electronic Commerce, Denver, Colorado (1999) 158-166

141. Senn, J.A.: The emergence of m-commerce. Computer 33(12) (2000) 148-151

142. Smyth, B.: Case-base recommendation. In Brusilovsky, P., Kobsa, A., Nejdl, W. (eds.): The Adaptive Web: Methods and Strategies of Web Personalization, Lecture Notes in Computer Science, Vol. 4321. Springer-Verlag, Berlin Heidelberg New York (2006) this volume

143. Smyth, B., Cotter, P.: The plight of the navigator: solving the navigation problem for wireless portals. In De Bra, P., Brusilovsky, P., Conejo, R. (eds.): LNCS 2347, Adaptive Hypermedia and Adaptive Web Based Systems, Second Int. Conference (AH 2002). Springer-Verlag, Berlin Heidelberg New York (2002) 328-337

144. Stafford, T.F., Gillenson, M.L.: Mobile commerce: what it is and what it could be. Communications of the ACM 46(12) (2003) 33-34

145. Sun, J.: Information requirement elicitation in mobile commerce. Communications of the ACM 46(12) (2003) 45-47

146. Sun Microsystems, I.: Java 2 Platform Enterprise Edition, http://java.sun.com/j2ee/ (2002)

147. Sycara, K., Paolucci, M., Soudry, J., Srinivasan, N.: Dynamic discovery and coordination of agent-based Semantic Web services. IEEE Internet Computing 8(3) (2004) 66-73

148. Tam, K., Ho, S.: Web personalization: is it effective? Perspectives (September-October) (2003) 53-57

149. TeleMutuo: TeleMutuo, risparmiamo i tuoi soldi., http://www.telemutuo.it (2006)

150. Tilson, R., Dong, J., Martin, S., Kieke, E.: Factors and principles affecting the usability of four e-commerce sites. In: Proc. 4th Conf. on Human Factors and the Web, Basking Ridge, NJ, USA (1998)

151. TomTom: Tomtom go, http://www.tomtom.com (2004)

152. Tseng, M., Piller, T. (eds.): The customer centric enterprise. Advances in Mass Customization and personalization. Springer-Verlag, New York/Berlin (2003)

153. Turban, E., King, D., Lee, J., Viehland, D.: Electronic Commerce 2004: A Managerial Perspective. Prentice Hall (2004) 
154. Urbaczewski, A., Valacich, J., Jessup, L. (eds.): Mobile commerce. Opportunities and challenges. Volume 46. Communications of the ACM (2003)

155. van Setten, M., Pokraev, S., Koolwaaij, J.: Context-aware recommendations in the mobile tourist application COMPASS. In De Bra, P., Nejdl, W. (eds.): LNCS 3137, Adaptive Hypermedia and Adaptive Web-Based Systems, 3rd Int. Conference, AH2004. SpringerVerlag, Berlin Heidelberg New York (2004) 235-244

156. Venkatesh, V., Ramesh, V., Massey, A.P.: Understanding usability in mobile commerce. Communications of the ACM 46(12) (2003) 53-56

157. W3C: Web Services Definition Language, http://www.w3.org/TR/wsdl (2002)

158. W3C: Platform for Privacy Preferences (P3P) Project, http://www.w3.org/P3P/ (2006)

159. Wahlster, W.: Resource-adaptive interfaces to hybrid navigation systems (keynote talk). In De Bra, P., Brusilovsky, P., Conejo, R. (eds.): LNCS 2347, Adaptive Hypermedia and Adaptive Web Based Systems, Second Int. Conference (AH 2002). Springer-Verlag, Berlin Heidelberg New York (2002) 12-13

160. Witkowski, M., Pitt, J., Fehin, P., Arafa, Y.: Indicators of the effect of agent technology on consumer loyalty. In Stanford-Smith, B., Chiozza, E. (eds.): E-work and Ecommerce. Novel solutions and practices for a global networked economy. IOS Press (2001) 1165-1171

161. Zimmerman, J., Kurapati, K., Buczak, A., Schaffer, D., Gutta, S., Martino, J.: TV personalization system. Design of a TV show recommender engine and interface. In Ardissono, L., Maybury, M., Kobsa, A. (eds.): Personalized Digital Television. Targeting programs to individual users. Kluwer, Dordrecht (2004) 27-52 